\title{
BIOSORPTION OF NICKEL BY BARLEY STRAW
}

\author{
A Thesis Submitted to the College of \\ Graduate Studies and Research \\ in Partial Fulfillment of the Requirements \\ for the Degree of Master of Science \\ in the Department of Chemical Engineering \\ University of Saskatchewan \\ Saskatoon \\ By \\ Ayyasamy Thevannan
}

(C) Copyright Ayyasamy Thevannan, September 2009. All rights reserved. 


\section{PERMISSION TO USE}

In presenting this thesis/dissertation in partial fulfillment of the requirements for a Postgraduate degree from the University of Saskatchewan, I agree that the Libraries of this University may make it freely available for inspection. I further agree that permission for copying of this thesis/dissertation in any manner, in whole or in part, for scholarly purposes may be granted by the professor or professors who supervised my thesis/dissertation work or, in their absence, by the Head of the Department or the Dean of the College in which my thesis work was done. It is understood that any copying or publication or use of this thesis/dissertation or parts thereof for financial gain shall not be allowed without my written permission. It is also understood that due recognition shall be given to me and to the University of Saskatchewan in any scholarly use which may be made of any material in my thesis/dissertation.

Requests for permission to copy or to make other uses of materials in this thesis/dissertation in whole or part should be addressed to:

Head of the Department of Chemical Engineering

University of Saskatchewan

Saskatoon, Saskatchewan S7N 5A9

Canada 


\begin{abstract}
Nickel contaminated wastewater from plating industries is a major environmental concern. Current treatment methods are often expensive and can also create additional problems. Biosorption is an alternative treatment method that uses inexpensive biomaterials to sequester metals from aqueous solutions. In this study, acid washed barley straw (AWBS) was used for adsorbing nickel ions $\left(\mathrm{Ni}^{2+}\right)$ from simulated nickel plating wastewater. The adsorption process was rapid and the equilibrium was reached in about an hour. An increase in the initial nickel concentration increased the equilibrium nickel uptake, and the maximum uptake was found to be $8.45 \mathrm{mg} / \mathrm{g}$ of AWBS when the initial nickel concentration was1000 mg/L at pH 5. Nickel adsorption was favorable at room temperature than $5^{\circ} \mathrm{C}$ and $40^{\circ} \mathrm{C}$, better adsorption rate and equilibrium uptake was observed at $23^{\circ} \mathrm{C}$. Increasing the $\mathrm{pH}$ from 3 to 7 increased the equilibrium nickel uptake and the maximum uptake was observed at $\mathrm{pH} 7$, whilst the initial nickel ion concentration was 100 mg/L. The Freundlich isotherm model exhibited better fit with the equilibrium data than the Langmuir equation. Nickel was desorbed using hydrochloric acid solution at $\mathrm{pH} 2$ and the desorption efficiency was 86\%. FT-IR studies indicated the participation of hydroxyl, carboxyl and amide groups from cellulose, hemi-cellulose, protein and lignin of barley straw.
\end{abstract}




\section{ACKNOWLEDGEMENTS}

I sincerely thank my supervisor Dr. Catherine Niu, for the guidance, support and patience; from day one, receiving me at the airport and towards the end of the masters program. I express thanks to my committee members Dr. Gordon A. Hill and Dr. Mehdi Nemati, for their inputs and encouragement for conducting this research.

I thank the University of Saskatchewan, Natural Sciences and Engineering Research Council and Canada Foundation for Innovation for the financial support. I am also thankful to Dr. Richard W. Evitts for allowing me to attend his classes and Dr. Ajay Dalai for permitting me to use his lab. I also thank Dr. Sathyanarayan Naik and Mr. Prasant Rout for their help in experiments.

I express thanks to all the members of the Chemical Engineering Department, notably, Mr. Richard Blondin, Mr. Dragan Cekic, Ms. Jean Horosko and Ms. Kelly Bader for their support, from time to time. I sincerely thank Mr. Barry Goetz of the Department of Soil Science, for his help in AAS analysis.

I thank my friend Venu Shamugavel and for his invaluable support to me in settling in the new environment. I am also thankful to Venkat Sridharan, Aravinda Kumar Napa, Nancy Bawa, Kishari Nalinda, Pardeep Kumar, Glyn Kennel and Hai-Dong Wang for their help and friendship. 


\section{DEDICATION}

This thesis is dedicated

To

My parents

Teachers

and

My beloved friend

Rajesh S. Ramasamy 


\section{TABLE OF CONTENTS}

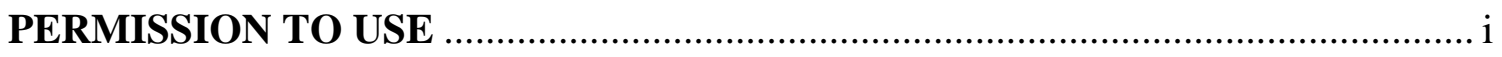

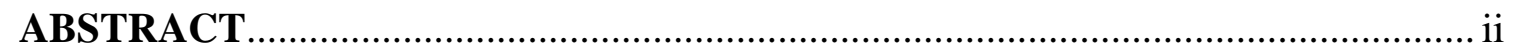

ACKNOWLEDGEMENTS ............................................................................ ii

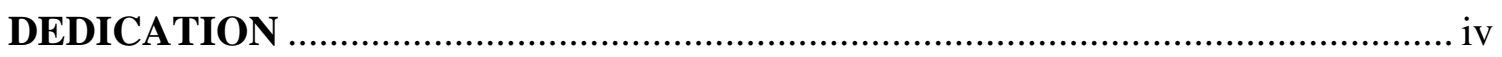

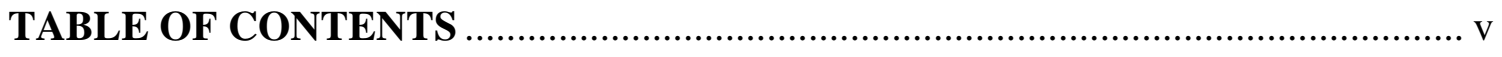

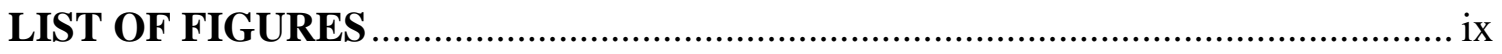

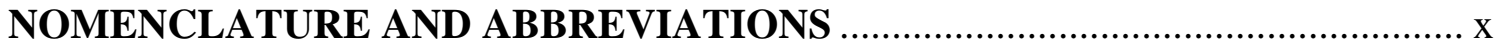

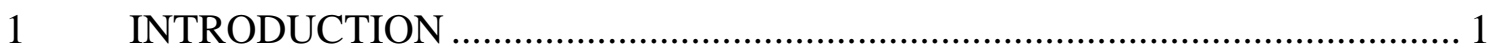

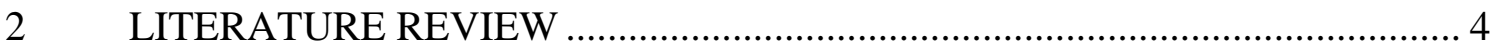

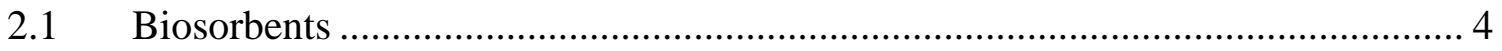

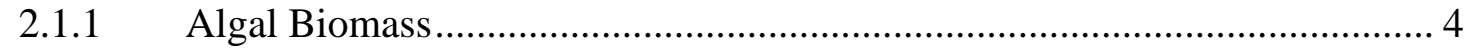

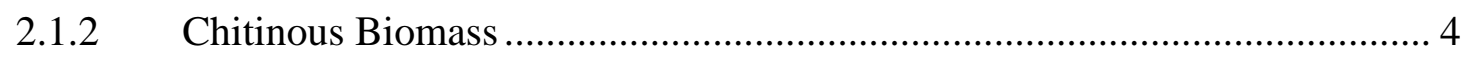

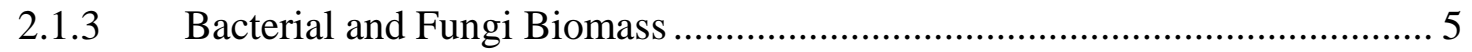

2.1.4 Plant Materials and Agricultural By-Products......................................... 5

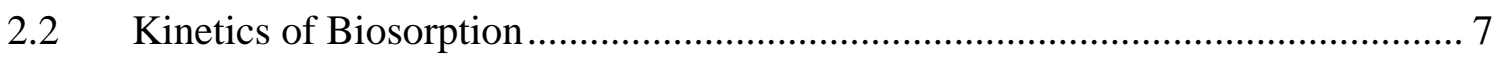

2.2.1 Effect of Biosorbent Particle Size.......................................................... 8

2.2.2 Effect of Initial Metal Concentration........................................................ 9

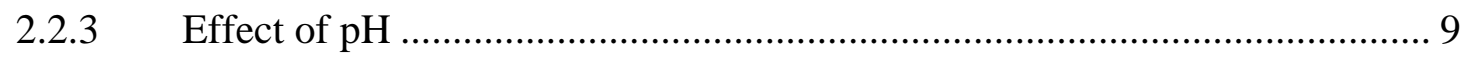

2.2.4 Effect of Temperature ...................................................................... 10

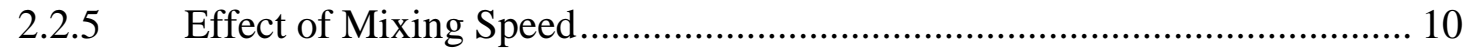

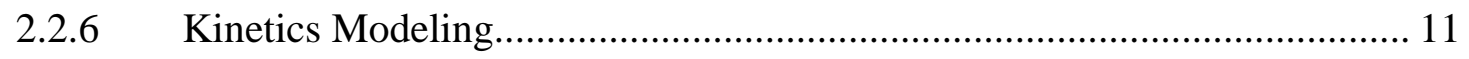

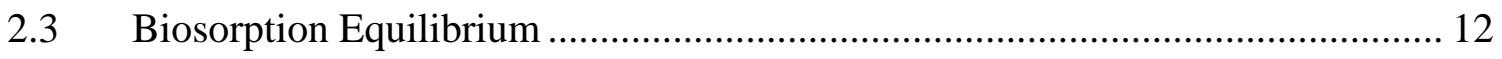

2.3.1 Effect of Particle Size .......................................................................... 13

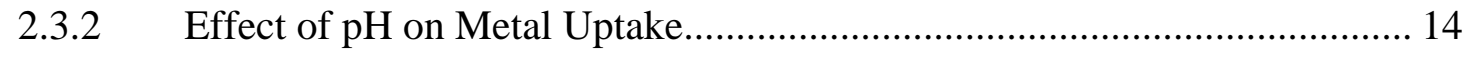

2.3.3 Effect of Biosorbent Concentration on Equilibrium Metal Uptake............. 15 
2.3.4 Effect of Temperature on Equilibrium Metal Uptake.................................... 16

2.3.5 Equilibrium Modeling ............................................................................ 16

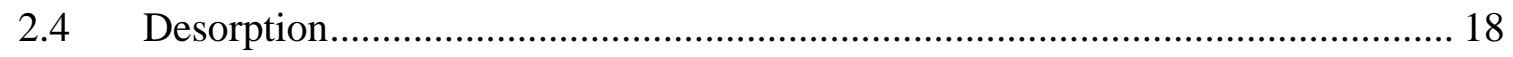

$2.5 \quad$ Mechanisms of Biosorption .......................................................................... 19

3 KNOWLEDGE GAP AND OBJECTIVES.................................................. 22

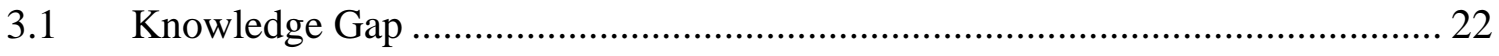

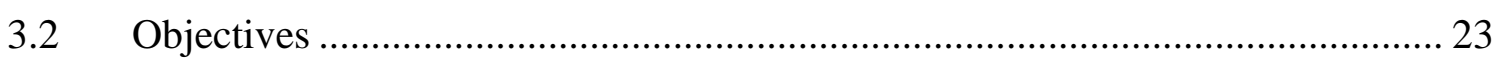

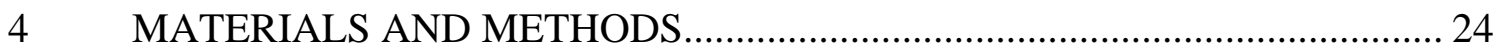

4.1 Biosorbents Preparation...................................................................................... 24

4.1.1 Raw Barley Straw Preparation (RBS) ………………………................... 24

4.1.2 Acid Washed Barley Straw Preparation (AWBS) ......................................... 24

$4.2 \quad$ Nickel Solution Preparation...................................................................... 24

4.3 Biosorption Experiments ………………………...................................... 25

4.4 Desorption Experiments .............................................................................. 26

4.5 Point of Zero Net Charge Experiments (PNZC).................................................. 27

4.6 Analyses ............................................................................................... 27

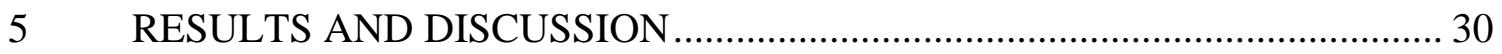

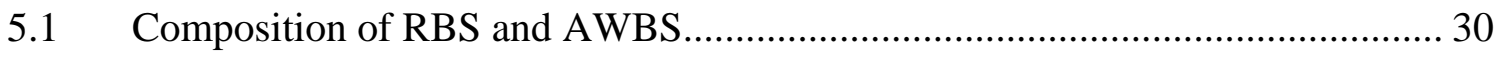

$5.2 \quad$ Point of Zero Net Charge (PZNC) ................................................................... 31

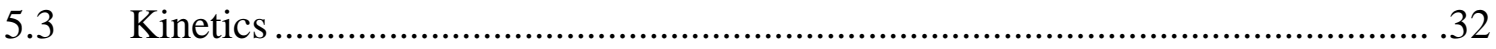

5.3.1 Particle Size Effect.................................................................................... 32

5.3.2 Effect of Initial Nickel Concentration ...................................................... 34

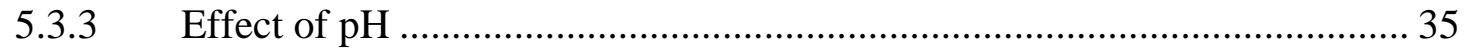

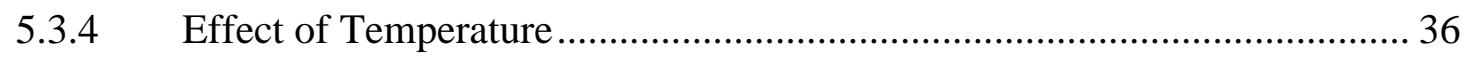

5.3.5 Mass Transfer Modeling .......................................................................... 37

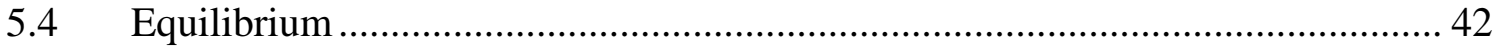


5.4.1 Effect of Ionic Strength.................................................................. 42

5.4.2 Effect of Particle Size .............................................................................. 44

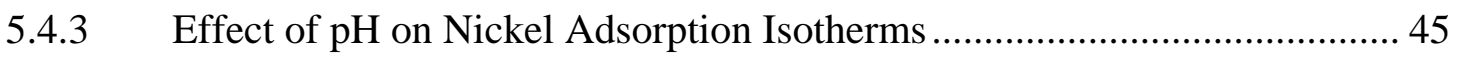

5.4.4 Effect of pH on Nickel Precipitation .................................................... 48

5.4.5 Effect of Temperature on Nickel Adsorption Isotherms ............................ 49

5.4.6 Adsorption Isotherm Modeling.............................................................. 51

5.5 Desorption of Nickel Adsorbed on AWBS.................................................... 56

5.6 Fourier Transform Infra Red Spectroscopy Analysis (FT-IR) .......................... 56

6 CONCLUSIONS AND RECOMMANDATIONS ....................................... 59

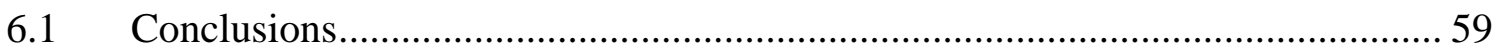

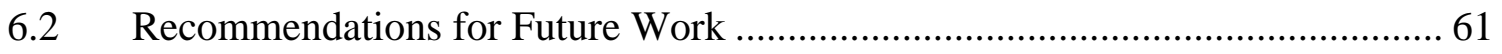

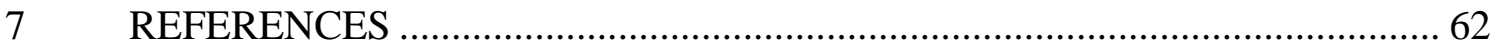




\section{LIST OF TABLES}

Table 2.1: Agriculture By-Products Used as Biosorbents ............................................ 6

Table 2.2: Chemical Composition of Some Important Straws ....................................... 7

Table 5.1: Element Present in RBS and AWBS .......................................................... 30

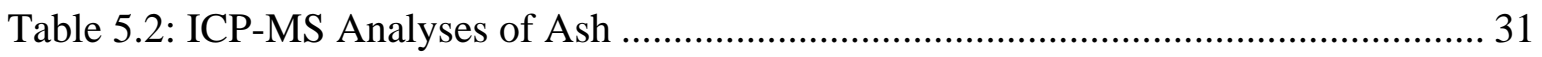

Table 5.3: Model Parameters: Effect of Particle Size on Nickel Adsorption Kinetics........ 39

Table 5.4: Model Parameters: Effect of pH on Nickel Adsorption Kinetics...................... 40

Table 5.5: Model Parameters: Effect of Temperature on Nickel Adsorption Kinetics ....... 42

Table 5.6: Biosorbents Reported on Nickel Adsorption.............................................. 51

Table 5.7: Simulation Results Using the Freundlich Equation (room temperature) ........... 52

Table 5.8: Simulation Results Using the Langmuir Equation (room temperature)............ 53

Table 5.9: Simulation Results Using the Freundlich Equation ( $\mathrm{pH} 5.0 \pm 0.1) \ldots \ldots \ldots \ldots \ldots . . . . . . .54$

Table 5.10: Simulation Results Using the Langmuir Equation ( $\mathrm{pH} 5.0 \pm 0.1$ ) ................... 55 


\section{LIST OF FIGURES}

Figure 4.1: Biosorption - Experimental Set-Up........................................................ 26

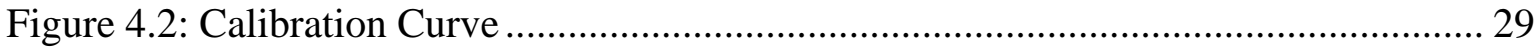

Figure 5.1: Determination of Point of Zero Net Charge of AWBS .................................. 32

Figure 5.2: Effect of Particle Size on Kinetics of Nickel Adsorption .............................. 33

Figure 5.3: Effect of Initial Nickel Concentration...................................................... 34

Figure 5.4: Effect of pH on Nickel Adsorption Kinetics ............................................. 35

Figure 5.5: Effect of Temperature on Kinetics ......................................................... 36

Figure 5.6: Modeling the Effect of Particle Size on Nickel Adsorption Kinetics .............. 38

Figure 5.7: Modeling the Effect of $\mathrm{pH}$ on Nickel Adsorption Kinetics ........................... 40

Figure 5.8: Modeling the Effect of Temperature on Nickel Adsorption Kinetics.............. 41

Figure 5.9: Effect of Ionic Strength on Nickel Uptake............................................. 43

Figure 5.10: Effect of Particle Size on Nickel Uptake by Barley Straw ............................ 45

Figure 5.11: Effect of pH on Nickel Adsorption Isotherms ....................................... 46

Figure 5.12: Effect of $\mathrm{pH}$ on Nickel Uptake.......................................................... 47

Figure 5.13: Effect of $\mathrm{pH}$ on Nickel Precipitation..................................................... 48

Figure 5.14: Effect of Temperature on Nickel Adsorption Isotherms ............................. 50

Figure 5.15: Simulation Results Using the Freundlich Equation (room temperature) ........ 52

Figure 5.16: Simulation Results Using the Langmuir Equation (room temperature)......... 53

Figure 5.17: Simulation Results Using the Freundlich Equation ( $\mathrm{pH} 5.0 \pm 0.1$ )................ 54

Figure 5.18: Simulation Results Using the Langmuir Equation ( $\mathrm{pH} 5.0 \pm 0.1$ ) ................. 55

Figure 5.19: FT-IR Spectra of Barley Straw Control and $\mathrm{Ni}^{2+}$-Loaded Barley Straw ........ 57 


\section{NOMENCLATURE AND ABBREVIATIONS}

\section{Nomenclature}

$a$ - specific surface area of biosorbent granules per unit volume of reactor $\left(\mathrm{m}^{2} / \mathrm{m}^{3}\right)$

b - coefficient related to the affinity between the sorbent and sorbate

$C$ - concentration of metal in the solution at time $\mathrm{t}(\mathrm{mg} / \mathrm{L})$

$C_{0}$ - initial concentration of metal in the solution $(\mathrm{mg} / \mathrm{L})$

$C^{*}$ - equilibrium concentration of sorbate remaining in the solution $(\mathrm{mg} / \mathrm{L})$

k - Freundlich constant (mg/g)

$K_{L}$ - external film mass transfer coefficient ( $\left.\mathrm{m} / \mathrm{min}\right)$

$K_{L} a$ - volumetric mass transfer coefficient (1/min)

n - Freundlich constant

q - sorption uptake (mg/g)

$\mathrm{q}_{\max }$ - maximum sorbate uptake under the given conditions (mg/g)

S - quantity of biosorbent on dry weight basis (g)

$\mathrm{t}$ - time (min)

$\mathrm{V}$ - volume of the sorbate-bearing solution contacted with sorbent (L)

$W_{s}$ - biosorbent loading per unit volume of solution (g/L)

$\mathrm{X}$ - concentration of nickel standard solution 


\section{Abbreviations}

AAS - atomic absorption spectrometer

ASTM - American society for testing materials

AWBS - acid washed barley straw

FBCS - free biomass of Chlorella sorokiniana

FT-IR - Fourier transform infra-red

ICP-MS - inductively coupled plasma mass spectrometry

IPA - iso-propyl alcohol

LIBCS - loofa sponge-immobilized biomass of Chlorella sorokiniana

PZNC - point of zero net charge

RBS - raw barley straw 


\section{INTRODUCTION}

Nickel is an important, widely used abundantly available metal (El Hajjami, Gigandet et al. 2008; Kim and Hwang 2008; Tracey 1988). Industrial activities for the production and use of nickel cause health hazards and environmental pollution. Some nickel compounds have been implicated as potential carcinogens (Richardson-Boedler. 2007). Nickel containing wastewater is usually generated by the electroplating and mining industries; as the North American electroplating industry registered significant growth in the past decade, and with the advent of ecological awareness, it's imperative to focus more research on the wastewater generated from nickel plating (Doniec 2008; Volesky 2003).

Nickel plating is an essential process as it has numerous engineering and decorative applications. Nickel coating is generally carried out by using Watts nickel solution, in which nickel sulfate is one of the main constituents (Bolger 2002; Karppinen 2000). After coating, the plated components are rinsed in several water baths; this process generates large quantities of nickel containing wastewater. It is an accepted fact that treating wastewater for recycling will benefit the environment as well as decrease the raw material and operating costs resulting from the disposal of wastewater; for instance, a case study for A.G. Simpson Ltd, Ontario, Canada, established that the water consumption was reduced by 30,000 cubic meters per month, and therefore the estimated annual savings were 
\$200,000-250,000 Canadian dollars (Force 2001). Ion exchange, electro-winning, evaporation, reverse osmosis and electro-dialysis are the technologies currently used for treating nickel plating wastewaters (Lindsey 1993). Most of these treatment methods are expensive; there is a need to develop cost-effective technologies for treating this wastewater.

Biosorption is a process that uses inexpensive biomaterials to sequester metals from aqueous solutions and the biomaterials used in this process are termed as biosorbents (Volesky 2003). Biosorption process have been used to sequester precious, heavy, toxic and radioactive metal ions such as $\mathrm{Ag}, \mathrm{Au}, \mathrm{Cd}, \mathrm{Co}, \mathrm{Cr}, \mathrm{Cu}, \mathrm{Fe}, \mathrm{Hg}, \mathrm{Mn}, \mathrm{Ni}, \mathrm{Pb}, \mathrm{Pd}, \mathrm{Pt}, \mathrm{U}$, Th and Zn (Davis 2003; Niu 2003; Niu 2003; Volesky 2003; Holan 1994; Holan 1993; Niu 1993; Viraraghavan 1993; Tobin 1984).

Biosorbents can be sourced from waste biomaterials generated from agriculture, food and pharmaceutical industries; this makes biosorption an economically alternative treatment method. Biomaterials containing acidic groups such as carboxyl, hydroxyl, and weak basic groups such as amides/amines are efficient in adsorbing metal ions (Niu 2003; Volesky 1990).

Previous research showed that there are three major factors affecting metal biosorption behavior (Schiewer 1996) .

1. The characteristics of biosorbents - surface area, porosity and number of functional groups such as carboxyl, hydroxyl and amino groups.

2. The characteristics of metals that are being sorbed; this includes metal speciation in solution. 
3. Operational parameters such as $\mathrm{pH}$, ionic strength, temperature and interference of other ions.

Although a few attempts were made to study the biosorption of nickel ions from wastewater (Vijayaraghavan 2005; Volesky 1990), the industrial applications are still limited; it is necessary to develop biosorbents with high uptake capacity for targeted metal ion species and to establish a cost-effective biosorption process. 


\section{LITERATURE REVIEW}

Biosorption is relatively a new technology and the feasibility of this process depends on the development of new biomaterials (Volesky 2003). Various biomaterials such as algal, chitinous, bacterial and fungi biomass, and other plant materials were tested as biosorbents in the past (Niu 2001; Volesky 1990).

\subsection{Biosorbents}

\subsubsection{Algal Biomass}

Algae are the most common biomass on the earth. Out of many varieties of algae, brown algae (Phaeophyta), red algae (Rhodophyta), green algae (Chlorophyta) and Diatoms (Bacillariophyceae) are important. Marine algae shows very good metal uptake; the biopolymers present in the marine algae are responsible for the high metal uptake (Volesky 2003).

\subsubsection{Chitinous Biomass}

Biomaterials which contain chitin are accepted as good biosorbents for metals (Niu 2001). Anionic metal species like chromate, vanadate and gold cyanide are better 
adsorbed by the chitin containing biomass (Niu 2003). Extraction of chitin and chitosan is expensive, so the chitin containing biological materials like waste crab shells are used for biosorption (Volesky 2003).

\subsubsection{Bacterial and Fungi Biomass}

Bacterial and fungi biomass are obtained as industrial by-products (Volesky 2003). The efficiency of this microbial biomass to bind various metal ions from the aqueous solution has been thoroughly studied in the past. Although they show good metal ion uptake, have some disadvantages; they contain impurities so complex treatments are required, their quality is inconsistent and granulation is neccessary which increases the cost of the biomass.

\subsubsection{Plant Materials and Agricultural By-Products}

Wide variety of plant materials like canola meal, moss, peat, water hyacinth were tested for their efficiency in biosorption (Volesky 2003; Al-Asheh and Duvnjak 1999). Apple residue, banana pith, corn cobs, coconut husks, sugarcane bagasee, olive mill solid residue, rice husk, wheat straw, peanut skins, spent grain, tea leaves and similar plant byproducts, and activated carbon derived from the by-products of plants were also studied (Chojnacka 2006; Ho 2006).

Though many types of plant materials were studied in biosorption, hardly a few attempts were made (Table 2.1) to study the biosorption behavior of agricultural byproducts. Cereals are the of majority crops cultivated on more than $70 \%$ of the agricultural 
land and wheat, rice, maize and barley are the predominant cereal crops; 154 million tons of barley was produced in 2004 (Cgiar 2005; University of Saskatchewan 2002). Thus barley straw is readily available at low price; it can be used as biosorbent. The composition of some important straws are shown in Table 2.2 (Lo'pez 2005). It is observed that barley straw possesses high lignin and crude protein content among the reported straws and the systematic study on nickel biosorption using barley straw is limited (Pehlivan et al. 2009; Vega et al. 2009; Larsen 1981).

Table 2.1: Agriculture By-Products Used as Biosorbents

\begin{tabular}{cccc}
\hline Biosorbents & Targeted Chemicals & $\begin{array}{c}\text { Max Uptake } \\
\text { (mg/g) }\end{array}$ & Reference \\
\hline Brazil nut shells & Nickel II & 7.87 & (Basso 2002) \\
Barley straw & Nickel II & 6.40 & (Larsen 1981) \\
Barley straw & Copper II & 4.64 & (Pehlivan et al. 2009) \\
Barley straw & Lead II & 23.20 & (Pehlivan et al. 2009) \\
Rice bran & Nickel II & 44.85 & (Zafar 2007) \\
Rice husk & Nickel II & 5.52 & (Krishnani 2008) \\
Grape stalks waste & Nickel II & 10.62 & (Miralles 2008) \\
Tobacco dust & Nickel II & 24.48 & (Qi 2008) \\
Orange peel & Nickel II & 75.14 & (Li 2008) \\
Cassia fistula & Nickel II & 188.37 & (Hanif 2007) \\
Olive stone waste & Nickel II & 2.13 & (Fiol 2006) \\
Wheat straw & Chromium III & 20.0 & (Chojnacka 2006) \\
Wheat straw & Reactive dyes & 5 & (Robinson 2002) \\
Oat biomass & Chromium VI & 59.96 & (Gardea-Torresdey 2000) \\
\hline
\end{tabular}


Table 2.2: Chemical Composition of Some Important Straws (Lo'pez 2005)

\begin{tabular}{cccc}
\hline Type of straw & $\begin{array}{c}\text { Organic matter } \\
\text { (g/kg) }\end{array}$ & $\begin{array}{c}\text { Crude protein } \\
\text { (g/kg) }\end{array}$ & $\begin{array}{c}\text { Lignin } \\
(\mathbf{g} / \mathbf{k g})\end{array}$ \\
\hline Barley & 938 & 33 & 68 \\
Wheat & 946 & 27 & 53 \\
Maize & 933 & 36 & 46 \\
\hline
\end{tabular}

\subsection{Kinetics of Biosorption}

In general, kinetics of biosorption is referred to as adsorption rate study. The rate of adsorption is strongly influenced by factors such as the structure of biosorbents, particle size, adsorption temperature, solution $\mathrm{pH}$, shaking rate and initial metal concentration (Rahman and Islam 2009; Ofomaja and Ho 2008; Pamukoglu and Kargi 2007; Volesky 2003).

Fogler explains that the rate of mass transfer of reactants and products between the fluid and the catalytic surface usually controls the rate of reactions (Fogler 1999). Mass transfer refers to a process in which diffusion takes place; diffusion can be defined as "the spontaneous intermingling or mixing of atoms or molecules by random thermal movement” (Fogler 1999). The molecules of a particular species in the same phase will forever diffuse from higher concentration to lower concentration if there are no influences of other factors such as heat, electricity and gravity, etc. The diffusion or mass transfer resistances are classified into two types, namely, external and internal resistance. The external mass transfer resistance deals with the diffusion of reactants between the bulk fluid and the outer surface of the catalyst and the internal mass transfer resistance explains the diffusion of the 
reactants from the external surface of the pellet to the interior (Fogler 1999). The external and internal mass transfer resistances of the biomass particles are the primary concerns for adsorption kinetics (Volesky 2003); however, whether the adsorption rate is controlled by mass transfer rate or intrinsic adsorption rate depends on the particular metal and specific biomass.

\subsubsection{Effect of Biosorbent Particle Size}

The smaller biosorbent particles have higher specific surface area and low mass transfer resistance than the larger biosorbents (Daifullah et al. 2004). Adsorption is a surface phenomenon; generally, sorbents with higher surface area should adsorb faster than that of sorbents having lower surface area. Daifullah et al. reported that the smaller and fine particles of the activated carbon adsorbent prepared from biomass material exhibited better adsorption rate and uptake than the larger particles of the same adsorbent.

Volesky and his colleagues studied the effect of particle size on uranium and cadmium biosorption by Sargassum biomass (Volesky 2003). Uranium adsorption was performed using Sargassum biomass of sizes $0.5-0.7 \mathrm{~mm}, 1.0-1.4 \mathrm{~mm}$ and native whole (not cut) seaweed. Cadmium sorption was studied using $0.5-0.7 \mathrm{~mm}, 0.84-1.00 \mathrm{~mm}$ and $1.0-1.4 \mathrm{~mm}$ of the same biomass. The researchers did not observe any significant difference in sorption rate for the two metal ion species among the tested particle sizes.

Cossich et al. (2002) also studied the biosorption of chromium with Sargassum biomass and reported that the rate of biosorption was independent on the particle size of the biomass. So, it can be stated that the influence of biomass size over the rate of biosorption depends on the particular metal ion and the biomass. 


\subsubsection{Effect of Initial Metal Concentration}

Chojnacka (2006) studied the effect of initial metal concentration on wheat straw by varying the initial Chromium-III concentration from 100 to $300 \mathrm{mg} / \mathrm{kg}$ and reported that the adsorption rate was increased with the increase in the initial metal ion concentration.

Zhou et al. (2007) studied the effect of initial chromium (VI) ion concentration using dead Bacilus licheniformis biomass. They varied the initial concentration from 20 to $300 \mathrm{mg} / \mathrm{L}$. It was demonstrated that higher initial chromium concentration provided a significant driving force, improved adsorption rate and equilibrium uptake. However, the removal efficiency of the biomass was reduced as the concentration of metal ions increased from 20 to $300 \mathrm{mg} / \mathrm{L}$ with constant amounts of biomass in the system (Zhou et al. 2007).

\subsubsection{Effect of pH}

Chojnacka (2006) studied the effect of pH on chromium ion adsorption by wheat straw and grass. He reported that the adsorption rate and the chromium uptake were increased when the $\mathrm{pH}$ was increased from 3 to 5 . Antunes et al. (2003) reported that the solubility of metal ions is strongly influenced by the $\mathrm{pH}$ of the solution. Niu reported that the solution $\mathrm{pH}$ influences the speciation of the metals and the active sites of the biomass (Niu 2002). Adsorption of anionic metals are favored at a lower $\mathrm{pH}$ range of 1.5-4, but cationic metals sequestration are preferred at $\mathrm{pH}$ above 4.5, hence it indicates that for cationic metal ions such as nickel, the biosorption system should be carried out above $\mathrm{pH}$ 4.5 . 


\subsubsection{Effect of Temperature}

According to Arrhenius, when the temperature of a reaction is increased, the rate constant increased and the reaction rate also increased (Fogler 1999). Zhou et al. studied Chromium (VI) biosorption by dead Bacillus licheniformis biomass and reported that the adsorption rate was accelerated when the temperature was elevated, and the metal uptake also increased by the effect of the rise in temperature (Zhou et al. 2007). Volesky studied cobalt adsorption by brown alga biomass and noted that the equilibrium uptake increased with an increase of temperature from $4^{\circ} \mathrm{C}$ to $40^{\circ} \mathrm{C}$, (Volesky 2003). Uslu and Tanyol (2006) studied the equilibrium and thermodynamic parameters of biosorption of lead (II) and copper (II) ions onto Pseudomonas putida; lead (II) and copper (II) adsorption rate increased when the temperature was increased from 20 to $25^{\circ} \mathrm{C}$ and 20 to $30^{\circ} \mathrm{C}$ respectively. A subsequent increase in temperature reduced the adsorption rate. All these observations indicate the significance of temperature on biosorption, and the adsorption process may be accelerated or decelerated with the increase of temperature, depending on the particular metal and the specific biomass.

\subsubsection{Effect of Mixing Speed}

As mentioned in Section 2.2, diffusion might play a role in determining the rate of the biosorption process; vigorous mixing can reduce or eliminate the external mass transfer resistance. By eliminating external mass transfer effect, the intra-particle mass transfer, an important rate controlling step, can be calculated experimentally (Antunes et al. 2003; Volesky 2003). External mass transfer resistance is directly related to the thickness of the 
immobile liquid layer, which can be reduced or eliminated by mixing or giving motion to the system.

Volesky and his colleagues performed biosorption experiments with different shaking rates with a biomass/liquid ratio of $2.0 \mathrm{~g} / \mathrm{L}$ (Volesky 2003). They observed that the adsorption rate increased with the increase in mixing speed up to a particular point; while a further increase in mixing speed had no significant effect on the adsorption rate. At this point external mass transfer resistance can be ignored. Antunes et al. also reported a similar observation (Antunes et al. 2003).

\subsubsection{Kinetics Modeling}

Modeling of adsorption kinetics helps in predicting the adsorption rate. With the intention of investigating adsorption mechanisms, a variety of kinetic models have been recommended. Lagergren's first-order equation, second-order reversible models, and pseudo-second-order models have been proposed to explain the kinetics of adsorption systems. However, these models do not reflect the effect of mass transfer (Ho 2006).

A film mass transfer model was described as follows (Shuler and Kargi, 2006):

$$
\frac{d C}{d t}=K_{L} a\left(C^{*}-C\right)
$$

where,

$K_{L}$ is the external mass transfer coefficient (m/min)

$a$ is the specific surface area of the biosorbent granules per unit volume of reactor $\left(\mathrm{m}^{2} / \mathrm{m}^{3}\right)$ 
$K_{L} a$ is the volumetric mass transfer coefficient $(1 / \mathrm{min})$

$C$ is the concentration of sorbate in the solution $(\mathrm{mg} / \mathrm{L})$

$C^{*}$ is the equilibrium concentration of sorbate in the solution $(\mathrm{mg} / \mathrm{L})$

$\mathrm{t}$ is the time (min)

When $\mathrm{t}$ approaches $0, C$ approaches the initial sorbate concentration in the solution $\mathrm{C}_{0}$.

Integration of Equation 2.1 yields the following

$$
\begin{aligned}
& \int_{C_{0}}^{C} \frac{d C}{C^{*}-C}=\int_{0}^{t} K_{L} a d t \\
& \ln \frac{C^{*}-C}{C^{*}-C_{0}}=-K_{L} a t
\end{aligned}
$$

then,

$$
C=C^{*}-\left[C^{*}-C_{0}\right] e^{-K_{L} a t}
$$

The volumetric mass transfer coefficients $K_{L} a(1 / \mathrm{min})$ are regressed by fitting the experimental data to Equation 2.4.

\subsection{Biosorption Equilibrium}

Equilibrium of a reaction is defined as the state at which the concentrations of reactants and products do not change with time ( Volesky 2003; Fogler 1999). At the state of equilibrium, the rate of forward reaction is same as that of reverse reaction; in the case of biosorption, the rate of adsorption is equal to the rate of desorption. There are two media 
in a sorption process; a solution of a sorbate and a solid sorbent material. Toxic chemicals, usually metals, to be sequestered from the solution are termed as the sorbate and the solid material used for metal sorption is referred to as the sorbent. The sorbent attracts and binds the metal species from the solution, this process continues until the system reaches equilibrium and the uptake of a biosorbent is assessed based on the quantity of sorbate retained in the biosorbents at equilibrium.

To determine the uptake, the amount of sorbate left in the solution is measured, and based on the mass balance concept, the sorbate uptake $\mathbf{q}$ is calculated.

$$
\mathrm{q}=\mathrm{V}\left(C_{0}-C^{*}\right) / \mathrm{S}
$$

Where,

$\mathrm{V}$ refers to the volume of the sorbate-bearing solution contacted with sorbent (L)

$C_{0}$ is the initial concentration of sorbate in the solution (mg/L)

$C^{*}$ is the equilibrium concentration of sorbate in the solution (mg/L)

$\mathrm{S}$ is the quantity of biosorbent on dry weight basis (g).

Biomass particle size, solution $\mathrm{pH}$, concentration of biosorbent, initial metal concentration, and temperature, are the important factors which affect equilibrium adsorption capacity (Chojnacka 2006; Akhtar 2004; Volesky 2003). By optimizing the above mentioned factors, an efficient biosorption process could be developed as in the case of new biomaterials for sorption, all of these factors have to be studied and optimized.

\subsubsection{Effect of Particle Size}

In general, smaller biosorbent particles which possess higher surface area tend to have a higher metal uptake in the adsorption process. The larger particles which have lower 
surface area tend to achieve a lower equilibrium metal uptake (Pamukoglu and Kargi 2007; Volesky 2003). However, it is not always true; Cossich et al. (2002) reported that they had not observed any significant change in equilibrium chromium uptake by varying the size of Sargassum sp. biomass. Another group of researchers studied on the biosorption of cadmium, copper, nickel, lead and zinc by Sargassum fluitans and Ascophylum nodosum and found that the larger particles exhibited greater metal uptake than the smaller biosorbent particles (Leusch et al. 1995). All the above observations indicate that the effect of particle size on equilibrium uptake depends on the particular biosorption system.

\subsubsection{Effect of $\mathrm{pH}$ on Metal Uptake}

The speciation of metal in the solution and the charge state of biosorbents are affected by $\mathrm{pH}$. Akhtar et al. studied the effect of $\mathrm{pH}$ on metal uptake in nickel biosorption with loofa sponge-immobilized biomass of Chlorella sorokiniana and free biomass of Chlorella sorokiniana; they conducted batch equilibrium studies at a $\mathrm{pH}$ range of 2.0-6.0 and observed very low nickel uptake ( $3 \mathrm{mg} / \mathrm{g}$ ) whereas at $\mathrm{pH} 2.0$, a higher uptake was attained at pH 4,5 and 6 (Akhtar et al. 2004). The researchers explained that at $\mathrm{pH} 2.0$ the adsorbent possesses more cationic charge, and cationic nickel ions could not bound effectively, the resulting uptake was low. When the $\mathrm{pH}$ was increased, more anionic charge becomes available to bind the cationic metal, and hence, higher uptakes were achieved at $\mathrm{pH} 4,5$ and 6, respectively.

Niu and Volesky (2003) reported that the anionic chromium uptake by crab shells was high at $\mathrm{pH}$ 2.0; the anionic metal uptake was decreased as the $\mathrm{pH}$ was increased from 2 to 3.6. This finding is in contrast with the phenomenon observed for the cationic metal 
(nickel). They explained that at low $\mathrm{pH}$, the crab shells possess more cationic charge to bind the anionic metal. As the $\mathrm{pH}$ is increased, the shells have less cationic charge to bind the anionic metal and hence exhibit a lower uptake .

From the above observations, it is understood that anionic metal species are better adsorbed at lower $\mathrm{pH}$ ranges whereas cationic metal species are better adsorbed at relatively high $\mathrm{pH}$ ranges. These experiments support the significance of $\mathrm{pH}$ on the equilibrium uptake of metal cation and anion species.

\subsubsection{Effect of Biosorbent Concentration on Equilibrium Metal Uptake}

Akhtar et al. (2004) conducted experiments to determine the effect of biosorbent concentration on the equilibrium uptake of sorbate. They conducted bath biosorption experiments with a fixed nickel (II) concentration of $25 \mathrm{mg} / \mathrm{L}$. They observed that the percentage of adsorbed nickel (II) was increased with the increase of free biomass of Chlorella sorokiniana (FBCS) sorbent from $0.5 \mathrm{~g} / \mathrm{L}$ to $1.0 \mathrm{~g} / \mathrm{L}$ and a maximum uptake was attained at $1.0 \mathrm{~g} / \mathrm{L}$. A gradual decrease in the uptake was observed while increasing the FBCS concentration up to $2.5 \mathrm{~g} / \mathrm{L}$; the researchers cited cell aggregation phenomenon for the decreased uptake. However, loofa sponge-immobilized biomass of Chlorella sorokiniana (LIBCS) sorbent continuously showed an increase in nickel (II) uptake with

the increase of its concentration up to $2.5 \mathrm{~g} / \mathrm{L}$ and maximum removal efficiency ( 100\%) attained at that sorbate concentration; the investigators explained that immobilization reduced biomass aggregation, and hence, the observed increased uptake. From these observations, it is noted that adsorption capacity may increase or decrease with the increase of biosorbent concentration depending on the specific biomass. 


\subsubsection{Effect of Temperature on Equilibrium Metal Uptake}

Chojnacka studied wheat straw and grass biosorbents for the biosorption of chromium (III) to determine the effect of temperature on the equilibrium uptake (Chojnacka 2006). He reported that the equilibrium metal uptake increased with the increase of temperature from $20^{\circ} \mathrm{C}$ to $60^{\circ} \mathrm{C}$, and the maximum uptake was achieved at $60^{\circ} \mathrm{C}$.

Uslu and Tanyol studied the effect of temperature on copper and lead biosorption by Pseudomonas putida biosorbent in batch system (Uslu 2006). The equilibrium uptake of copper increased as the sorption temperature was increased from $20^{\circ} \mathrm{C}$ and a maximum uptake was achieved at $30^{\circ} \mathrm{C}$, and further increase in temperature resulted in decreased uptake. In the case of lead, the equilibrium uptake was increased with the increase in sorption temperature from $20^{\circ} \mathrm{C}$ and a maximum uptake was observed at $25^{\circ} \mathrm{C}$, further increase in temperature to $30^{\circ} \mathrm{C}$ and $35^{\circ} \mathrm{C}$ resulted in a drastic decrease in lead uptake. It can be concluded that the effect of temperature on metal uptake depends on individual metal and specific biomass.

\subsubsection{Equilibrium Modeling}

Biosorption equilibrium is normally explained by isotherms, which are plots between equilibrium uptake and the respective sorbate concentration in the aqueous solution at specific temperature (Volesky 2003). Although numerous isotherm models were reported in literature, due to their simplicity, the Langmuir model and the Freundlich model are more frequently used (Maurya 2006). Langmuir and Freundlich isotherms are 
used for explaining the equilibrium phenomena of the important toxic metals such as nickel, chromium and copper (Uslu 2006; Cossich 2002).

\section{Langmuir Isotherm}

The Langmuir (1918) isotherm can be mathematically expressed as:

$$
\mathrm{q}=\mathrm{q}_{\max } \mathrm{b} C^{*} / 1+\mathrm{b} C^{*}
$$

Where,

$\mathrm{q}$ is the sorption uptake

$\mathrm{q}_{\max }$ is the maximum sorbate uptake under the given conditions,

$\mathrm{b}$ is a coefficient related to the affinity between the sorbent and sorbate,

$C^{*}$ is the equilibrium concentration of sorbate remaining in the solution

The Langmuir isotherm was the first model which hypothetically tested the adsorption of gases on solid surfaces. It assumes that sorption is a chemical adsorption. The Langmuir isotherm was developed based on the following assumptions: Sorption is a monolayer character and that there is no interaction between adsorbed species and the liquid medium. Even though Langmuir isotherm model does not describe the mechanism of a sorption process, it gives sorption uptakes and a fair reflection of common equilibrium sorption behaviors. Since this empirical model is simple and user friendly, it is widely used to describe the amount of sorbate uptake (Niu 2002).

\section{Freundlich isotherm}

The Freundlich (Freundlich 1907) isotherm is mathematically stated as

$$
\mathrm{q}=\mathrm{k} C^{* 1 / \mathrm{n}}
$$

Where, 
$\mathrm{q}$ is the sorption uptake

$\mathrm{k}$ and $\mathrm{n}$ are Freundlich constants

$C^{*}$ is the equilibrium concentration of sorbate remaining in the solution.

The Freundlich isotherm is also an empirical model. This isotherm is also widely used to describe the equilibrium uptakes of the biosorption processes (Volesky 2003).

\section{Other isotherm models}

Isotherm models such as Brunauer-Emmett-Teller (BET), Dubinin-Radushkevich (DR), Radke-Prausnitz, Reddlich-Peterson, Combination (Langmuir-Freundlich) have also been reported in literature (Volesky 2003). Maurya and Mittal reported the applicability of equilibrium isotherm models for the biosorptive properties of activated carbon-based materials (Maurya 2006). It is observed from their report that there are more than 15 different isotherm models already reported in the sorption literature.

\subsection{Desorption}

The purpose of the desorption process is to regenerate the biomass and obtain concentrated metal solution. Desorption is the process of removing adsorbed metal from the adsorbent (Volesky 2003; Niu 2002). It is the reverse process of adsorption, so that the conditions for desorption are opposite to the sorption experiments. First the biosorbent is loaded with metals. The metal-loaded biosorbent is treated with alkali or acid depending on the type of metal; anionic metal desorption is performed with an alkali $(\mathrm{NaOH})$ at alkaline $\mathrm{pH}$ and the cationic metal desorption is performed with a strong acid $(\mathrm{HCl})$ at 
acidic pH. Niu eluted anionic metals (chromate \& vanadate) from metal-loaded acid washed crab shells using sodium hydroxide $(\mathrm{NaOH})$ solution at pH 10 and achieved 100\% elution. Akhtar and his colleagues performed desorption experiments using $75 \mathrm{mM}$ hydrochloric acid (HCl) to elute nickel (II) from the loofa sponge-immobilized biomass of Chlorella sorokiniana, and eluted more than 99\% of adsorbed nickel ions from the biosorbent (Akhtar et al. 2004).

\subsection{Mechanisms of Biosorption}

The study of biosorption mechanisms helps in verifying the operative biosorption theory. Biosorption mechanisms can not be explained in a single mechanism as they involve biological materials which possess complex structures and many binding sites (Volesky 2003). In addition, one binding site can take part in dissimilar binding mechanisms, and hence, various mechanisms occur in combination. The mechanisms may differ as well with the influence of some external parameters such as solution $\mathrm{pH}$. The overall biosorption mechanisms can be explained by using the following terms: ion exchange, adsorption and micro-precipitation.

Ion exchange is the interchange of ions due to loss or gain of electrons in molecules or atomic species (Volesky 2003). Biosorption of metals with algal biomass is primarily involved through an ion exchange process.

The term “adsorption” refers to the binding of solute to unoccupied sites (Niu 2002; Fogler 1999). Adsorption is a surface phenomenon, the real sequestration may occur based on physical adsorption or chemisorption. 
Physical adsorption is not specific and the attracting forces are relatively weak. As a result, the extent of physical adsorption decreases quickly with the increase of temperature. Physisorption is highly reversible, and multi layer adsorption is possible. Biosorption of chromate and vanadate by crab shells is mainly through a physisorption mechanism.

In chemisorption, molecules adhere to a surface by forming a chemical bond. Chemisorption is well defined and the interactions involved in it are stronger than in physical adsorption. In this case, the adsorbed molecules are detained to the surface by strong covalent forces.

In a metallic solution, micro-precipitation of metals occurs when the solubility of sorbate attains its saturation point (Volesky 2003). This condition may be created by varying local physical conditions such as $\mathrm{pH}$ or by the biosorbent materials itself. Microprecipitation could contribute to a large extent for the overall removal efficiency of a biosorption system. The micro-precipitated metal is immobilized and collected by the sorbent and separated from the solution.

Many chemical groups of biosorbents, such as hydroxyl, carbonyl, carboxyl, sulfhydryl, thioether, sulfonate, amine, imine, amide, imidazole, phosphonate, phosphodiester have been proposed to bind metal ions (Volesky 2003). Volesky also pointed out the significance of any proposed chemical group for a specific biomass and a particular metal depending on the factors such as number of binding sites, availability and accessibility of the sites, attraction between the site and metal to be sorbed.

Mostly acidic binding sites such as hydroxyl, carboxyl, sulfhydryl, sulfonate and phosphonate are involved in cationic metal biosorption process (Volesky 2003). When 
solution $\mathrm{pH}$ exceeds the acid dissociation constant $\left(\mathrm{pK}_{\mathrm{a}}\right)$ of the acidic binding sites, protons are released and then the groups tend to attract cations. Basic functional groups such as amine, imine, amide and imidazole have been reported to contribute in binding of anionic metal species, at low $\mathrm{pH}$ values around 2 . 


\section{KNOWLEDGE GAP AND OBJECTIVES}

\subsection{Knowledge Gap}

Agriculture by-products are readily available at low-cost but their characteristics on nickel adsorption are yet to be systematically studied. Canada produces large amounts of barley straw, wheat straw and canola straw; some of which is used for animal feed, animal bedding and a major part of the straw is often considered as waste. It was reported that barley straw is used in ponds, lakes and aquariums to control algae and cyanobacteria and the straw is not toxic to fish and environment, the water is clean and clear all year long (Brownlee 2003). Barley straw contains hemi-cellulose, cellulose, lignin and protein (Mani 2002; Kulp 2000). The biomaterials containing carboxyl, hydroxyl and amino groups have good potential for removing nickel from aqueous solutions (Ahalya 2005; Lee 2004; Niu 2003). Although Larsen and Schieru (1981) examined nickel biosorption by barley straw, sufficient data on the effects of particle size, $\mathrm{pH}$, temperature and ionic strength on kinetics and equilibrium are not available. Therefore, a study of barley straw on nickel plating wastewater treatment is limited and in this work, barley straw will be systematically studied for nickel adsorption over a range of experimental conditions, for example, pH 3 to 8 and temperature $5^{\circ} \mathrm{C}$ to $40^{\circ} \mathrm{C}$, etc. 


\subsection{Objectives}

The overall objective of this work is to investigate the biosorption of nickel by barley straw. The detailed objectives of this research can be stated as follows:

1. Develop effective biosorbents for nickel adsorption.

2. Characterize the biosorbents on point of zero net charge (PZNC).

3. Examine the kinetics of nickel adsorption at different $\mathrm{pH}$, temperature and various sizes of biosorbents.

4. Demonstrate the equilibrium nickel ion uptake at different $\mathrm{pH}$, ionic strength and temperature.

5. Determine the efficiency of metal desorption.

6. Elucidate the nickel biosorption mechanism. 


\section{MATERIALS AND METHODS}

\subsection{Biosorbents Preparation}

\subsubsection{Raw Barley Straw Preparation (RBS)}

Rosser barley straw grown in Saskatoon was obtained from the Poultry Centre of the University of Saskatchewan. Barley straw was sun-dried, crushed and sieved to give three different sizes $(1.18 \mathrm{~mm}-3.35 \mathrm{~mm}, 0.425 \mathrm{~mm}-1.18 \mathrm{~mm}$ and less than $0.425 \mathrm{~mm})$ and then the straw was dried in an oven at $55^{\circ} \mathrm{C}$ and kept in desiccators.

\subsubsection{Acid Washed Barley Straw Preparation (AWBS)}

The dry raw barley straw of about $55 \mathrm{~g}$ was washed with $1 \mathrm{~L}$ of $1 \mathrm{~N}$ hydrochloric acid \& rinsed with de-ionized water till the $\mathrm{pH}$ of the washings reaches $4.5 \pm 0.1$, dried in an oven at $55^{\circ} \mathrm{C}$ and finally kept in desiccators. This procedure was adopted from the previous work performed with acid washed crab shells (Niu 2003).

\subsection{Nickel Solution Preparation}

Nickel solutions were prepared by dissolving hydrated nickel sulfate $\left(\mathrm{NiSO}_{4} \cdot 6 \mathrm{H}_{2} \mathrm{O}\right)$ in de-ionized water. Sulfuric acid $\left(0.1 \mathrm{M} \mathrm{H}_{2} \mathrm{SO}_{4}\right)$ and sodium hydroxide $(0.1 \mathrm{M} \mathrm{NaOH})$ 
were used for $\mathrm{pH}$ adjustment. All reagents used were of analytical grade (Sigma-Aldrich Corp.).

\subsection{Biosorption Experiments}

Sorption experiments were performed by using a titrator (Schott titro line easy). The experimental set-up is shown in Figure 4.1. The $250 \mathrm{~mL}$ of nickel sulfate solution was added to 2 gm of biosorbents (RBS or AWBS) and mixed by a stir bar at a speed of 700 rpm (this mixing speed was necessary for appropriate mixing of the biosorption system). The $\mathrm{pH}$ was automatically adjusted and the amount of sodium hydroxide added was also recorded. At periodic intervals, $0.25 \mathrm{~mL}$ solution was taken by using a $0.50 \mathrm{~mL}$ syringe (Hamilton Company) and the experiments were continued until the system reached equilibrium. The temperature of the reactor was controlled using a water circulator (VWR Signature Heated Circulator, Model 1160S). Nickel uptake was calculated by nickel mass balance in the system. Each of the experiments was performed in duplicate, and the variations of the duplicates were calculated in 95\% confidence interval and presented in figures using error bars. 


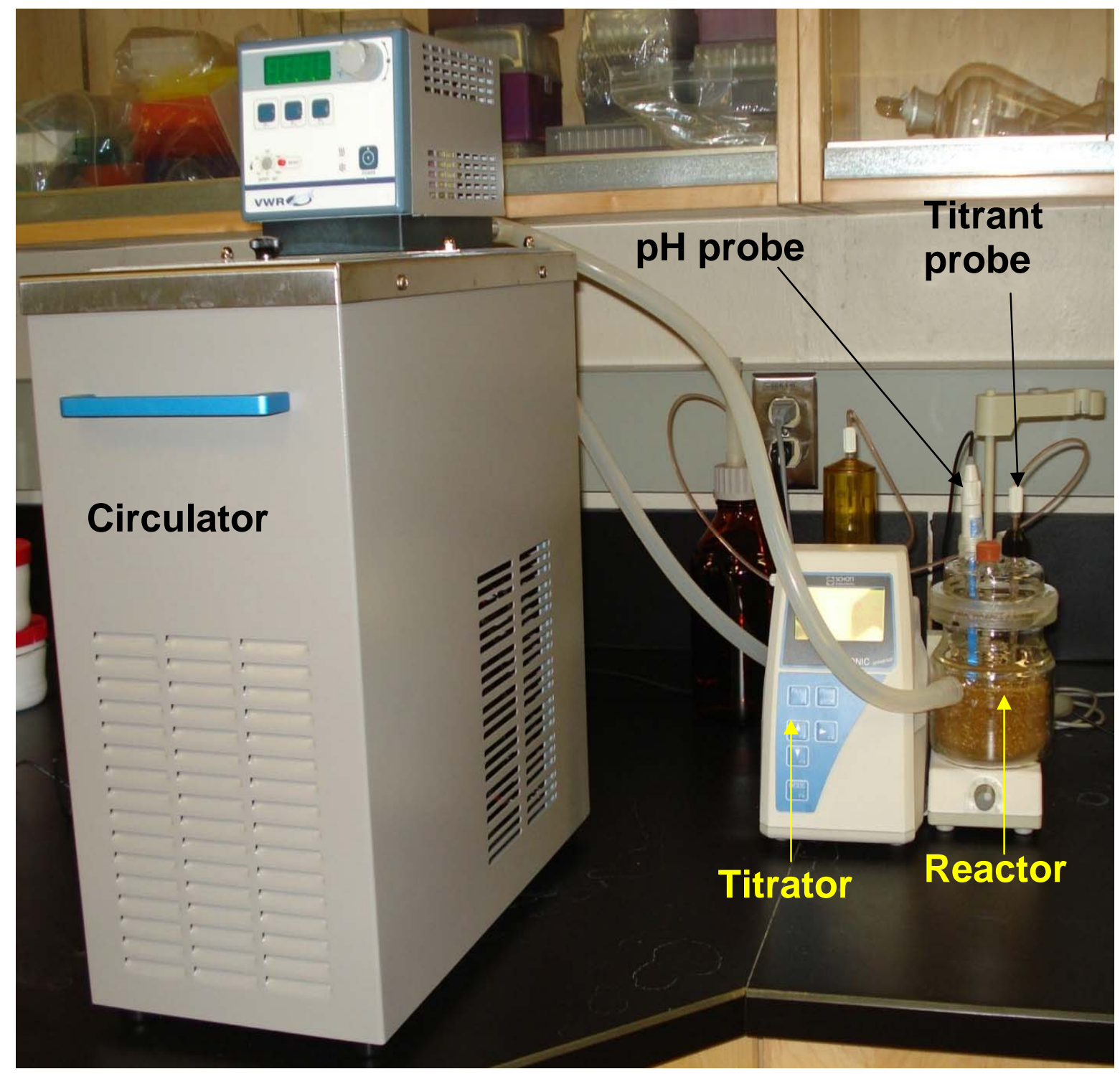

Figure 4.1: Biosorption - Experimental Set-Up

\subsection{Desorption Experiments}

The AWBS was first loaded with nickel, separated using a filter, dried and kept in desiccators. In a nalgene container $0.25 \mathrm{~g}$ of nickel-loaded AWBS was added to $10 \mathrm{ml}$ 
diluted hydrochloric acid solution at $\mathrm{pH} 2.0 \pm 0.1$ and the system was kept on a shaker (SK300 Rose Scientific Ltd.) for about 130 rpm for 24 hours. The volume of the solution was selected based on the minimum quantity of liquid required to immerse and well mix the biomass. The ratio of eluted nickel from the nickel-loaded biosorbent to the initially loaded nickel, called as elution or desorption efficiency was determined.

\subsection{Point of Zero Net Charge Experiments (PNZC)}

The point of zero net charge of the biosorbents was determined by a salt titration method (Davis 1978). The titration was achieved by observing the change in $\mathrm{pH}$ upon the addition of salt (sodium sulfate) to a biosorbent suspension. Each sample contained 20.0 $\pm 0.2 \mathrm{~mL}$ water or $0.1 \mathrm{M}$ sodium sulfate aqueous solution and $40 \pm 1 \mathrm{mg}$ dry biosorbent. The system was placed on an orbital shaker (JEIO TECH, model SK-300) at $130 \mathrm{rpm} / \mathrm{min}$ and run for 6 hours which is sufficient for reaching equilibrium at room temperature. At PZNC, there should be no change in $\mathrm{pH}$ upon the addition of the salt to the suspension. The $\mathrm{pH}$ was measured by a pH meter (ISTEK, model 915 PDC).

\subsection{Analyses}

Composition of Barley Straw: The common elements namely carbon (C), hydrogen (H), nitrogen $(\mathrm{N})$, oxygen $(\mathrm{O})$ and Sulfur $(\mathrm{S})$ were analyzed using a CHNS analyzer (PerkinElmer Elementar Vario III). Known quantities $(1.0 \mathrm{mg})$ of RBS or AWBS samples were used in a tin boat assortment for determining percentage composition of the above 
mentioned elements, except oxygen. The percentage composition of oxygen was calculated by means of difference.

Ash Content: The ash content of RBS and AWBS were determined as per ASTM 3174-04 procedure in a laboratory muffle furnace (Holpack, USA) (ASTM 2004). The $1.00 \mathrm{~g}$ of RBS or AWBS were taken in crucibles and kept in the muffle furnace and the temperature was maintained at $575 \pm 10^{\circ} \mathrm{C}$ for 4 hours. Then the crucibles were removed from the furnace and placed in the desiccators. This heating and cooling process was repeated until constant weights were obtained. The percentage ash content was calculated by subtracting the ash weight with the straw weight and divided by the straw weight and then multiplied by 100 .

Minerals Analysis: The common minerals present in the ashes of RBS and AWBS were determined by using an inductively coupled plasma mass spectrometry (Perkin Elmer Elan 5000 ICP-MS). A standard sample containing aluminum (Al), calcium (Ca), copper (Cu) iron (Fe), magnesium (Mg), manganese (Mn), phosphorus (P), Strontium (Sr) and zinc (Zn) were used for the calibration (signal intensity vs. mass to charge ratio) of ICP-MS.

FT-IR Analysis: A Fourier transform infra-red spectrometer (JASCO FT/IR-4100) was used for obtaining the information of the functional groups involved in biosorption of nickel by the AWBS. The nickel-loaded AWBS (contained $8.45 \mathrm{mg}$ of nickel per $\mathrm{g}$ of AWBS) or blank AWBS were analyzed using attenuated total reflection (ATR).

Nickel Concentration: The total nickel concentration in solution was determined by an atomic absorption spectrometer (Perkin-Elmer, AAnalyst 400) operated at the wavelength of $232 \mathrm{~nm}$. 
Atomic Absorption Spectrometer Calibration: The calibration was done using deionized water, 2.5, 5, 7.5 and $10 \mathrm{mg} / \mathrm{L}$ standard nickel solution. The calibration curve is shown in Figure 4.2.

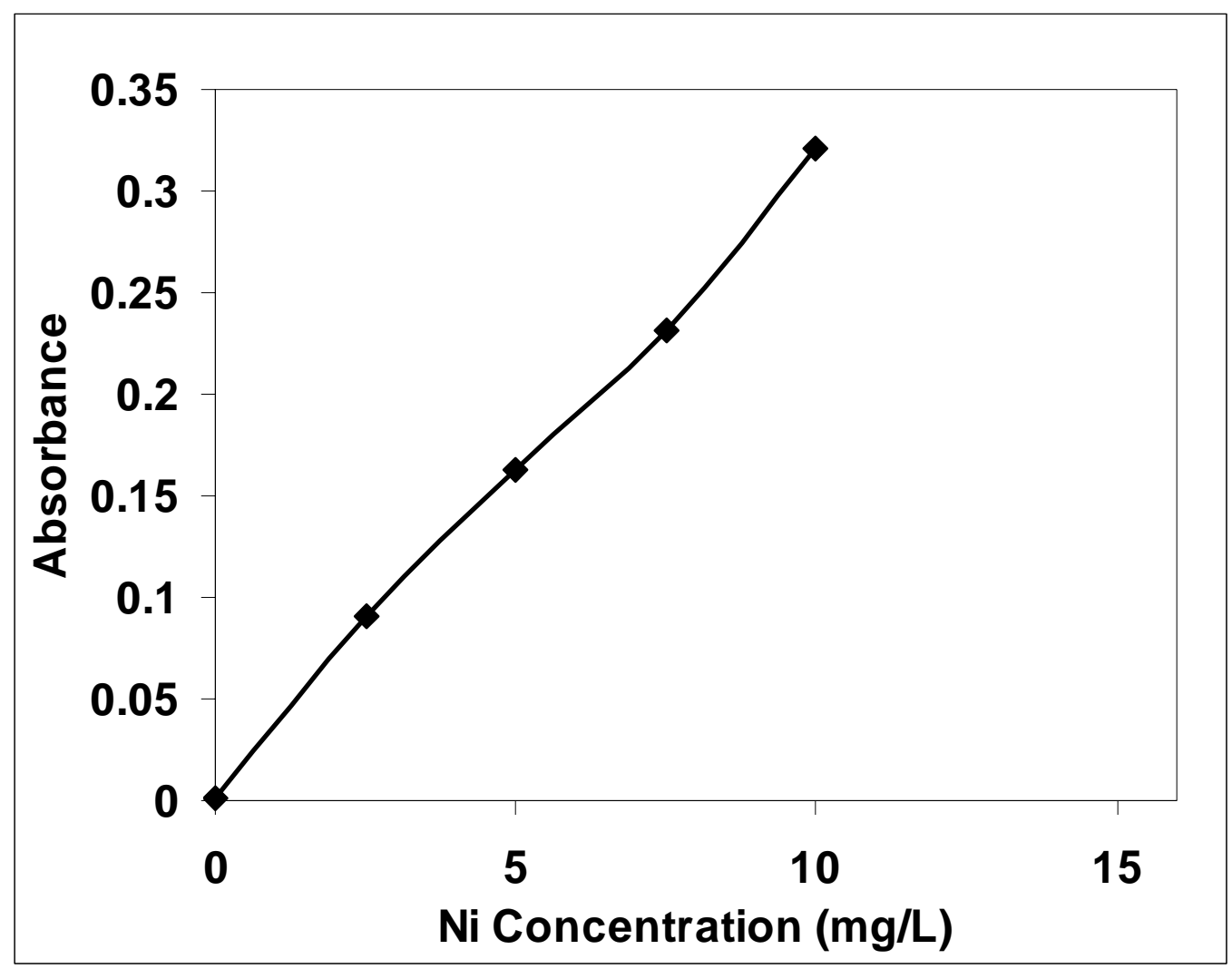

Figure 4.2: Calibration Curve

$$
\begin{array}{ll}
\text { Curve Fit } & =\text { Quadratic } \\
\mathrm{r} & =0.9988
\end{array}
$$

Absorbance $=-0.00004 X^{2}+0.03165 X+0.00442$

$X$ : concentration of $\mathrm{Ni}^{2+}$ standard solution 


\section{RESULTS AND DISCUSSION}

\subsection{Composition of RBS and AWBS}

The compositions of RBS and AWBS are reported in Table 5.1. Carbon, hydrogen and oxygen are the major elements present in both the biosorbents, which are also the key elements of cellulose, hemi-cellulose, lignin and protein contained in barley straw. No significant differences were observed in the amount of major elements present in RBS and AWBS. Acid treatment successfully reduced the ash content in the straw.

Table 5.1: Element Present in RBS and AWBS

\begin{tabular}{ccc}
\hline Element & RBS (\%) & AWBS (\%) \\
\hline Carbon & $45.18 \pm 0.15$ & $46.58 \pm 0.11$ \\
Hydrogen & $6.29 \pm 0.06$ & $6.38 \pm 0.02$ \\
Oxygen & $47.94 \pm 0.19$ & $46.74 \pm 0.07$ \\
Sulfur & $0.20 \pm 0.11$ & $0.13 \pm 0.03$ \\
Nitrogen & $0.39 \pm 0.00$ & $0.22 \pm 0.05$ \\
Ash & $9.80 \pm 1.00$ & $2.28 \pm 0.28$ \\
\hline
\end{tabular}


The Inductively Coupled Plasma Mass Spectrometry (ICP-MS) analyses further showed that RBS has higher amount of natural minerals than AWBS as shown in Table 5.2 , the values are within $5 \%$ variation. The acid washing process greatly reduced the minerals present in the RBS and hence to minimize the effect of interferences of other minerals and imperative to focus on nickel adsorption, AWBS biosorbent was selected for this study (Niu 2002).

Table 5.2: ICP-MS Analyses of Ash

\begin{tabular}{ccc}
\hline Element & $\begin{array}{c}\text { RBS (ppm)* } \\
\text { (Naik et al. 2009) }\end{array}$ & AWBS (ppm)* \\
\hline $\mathrm{Mg}$ & 16490 & 1220 \\
$\mathrm{Al}$ & 2583 & 583 \\
$\mathrm{P}$ & 17768 & 8373 \\
$\mathrm{Mn}$ & 288 & 66 \\
$\mathrm{Cu}$ & 134 & 122 \\
$\mathrm{Zn}$ & 95 & 75 \\
\hline
\end{tabular}

* Some important minerals have been compared

\subsection{Point of Zero Net Charge (PZNC)}

The charge state of biosorbent is crucial for effectively adsorbing ionic species of interest. Based on the fact, the acid washed barley straw is characterized in terms of the point of zero net charge (PZNC). The PZNC of barley straw particles is found to be around $\mathrm{pH}$ 4.4, which is the intersection of the two curves as shown in Figure 5.1. Hence the 
solution $\mathrm{pH}$ has to be higher than 4.4 so that barley straw has sufficient negative charged sorption sites to effectively bind nickel cations. It was confirmed by the effect of $\mathrm{pH}$ on nickel adsorption kinetics experiments, reported in section 5.3.3.

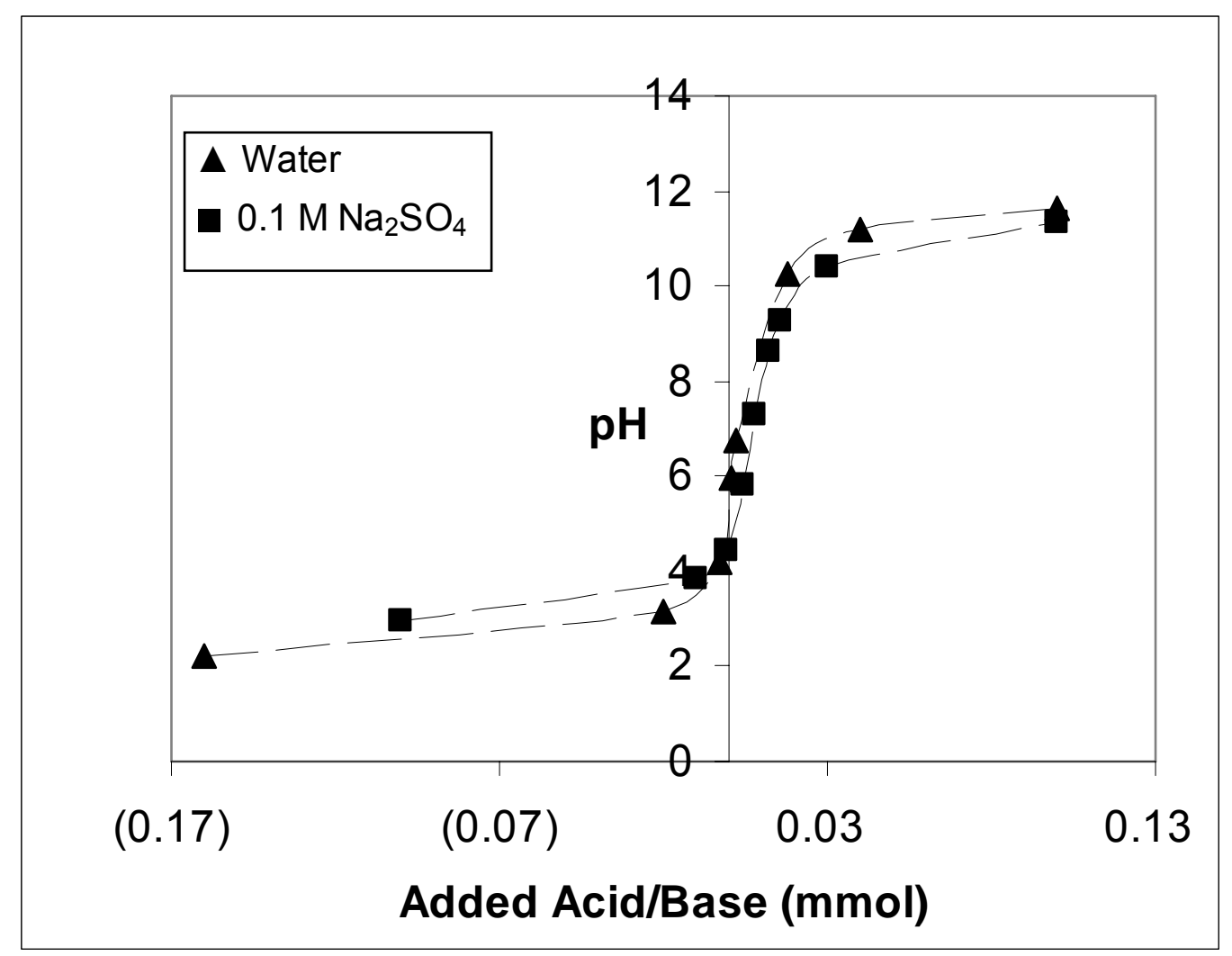

Figure 5.1: Determination of Point of Zero Net Charge of AWBS $20.0 \pm 0.2 \mathrm{~mL}$ water or $0.1 \mathrm{M} \mathrm{Na}_{2} \mathrm{SO}_{4}$ solution, $40 \pm 2 \mathrm{mg}$ AWBS, particle size of $1.18-3.35 \mathrm{~mm}, 23 \pm 1^{\circ} \mathrm{C}, 130 \mathrm{rpm}$ and $6 \mathrm{~h}$ of equilibration.

\subsection{Kinetics}

\subsubsection{Particle Size Effect}

The effect of particle size was examined by varying the size of AWBS from less than $0.425 \mathrm{~mm}, 0.425-1.18 \mathrm{~mm}$ and $1.18-3.35 \mathrm{~mm}$ and keeping all other conditions 
constant. The results are shown in Figure 5.2. The error bar represents a 95\% confidence interval. It is observed that the smallest particle size $(<0.425 \mathrm{~mm})$ achieved the highest adsorption rate and reached an equilibrium in 30 minutes whereas the other two sizes attained equilibriums about 60 minutes, with an initial nickel concentration of $100 \mathrm{mg} / \mathrm{L}$. The smaller biosorption particle size possesses a higher surface area and hence reached equilibrium in short time. This phenomenon is similar to that reported on copper (II) adsorption by powdered waste sludge. A decrease of the particle size from 231 to $53 \mu \mathrm{m}$ increased the adsorption rate and uptake. Volesky also reported similar observations (Pamukoglu and Kargi 2007; Volesky 2003).

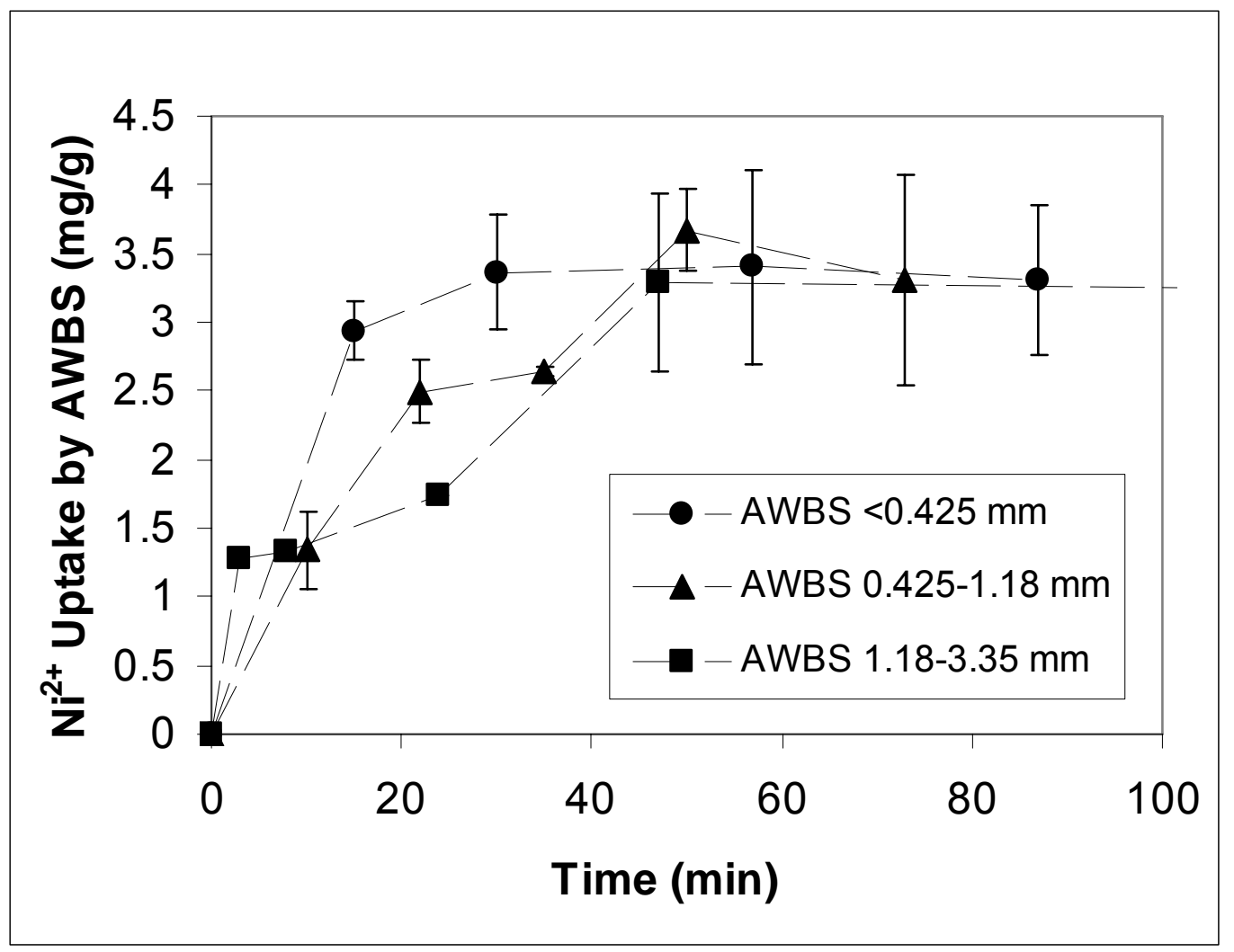

Figure 5.2: Effect of Particle Size on Kinetics of Nickel Adsorption $250 \mathrm{~mL}$ of $87 \pm 5 \mathrm{mg} / \mathrm{L}$ initial $\mathrm{Ni}^{2+}$ solution, $2 \mathrm{~g}$ of AWBS, particle sizes of $0.425-$ $1.18 \mathrm{~mm}, 23 \pm 1^{\circ} \mathrm{C}$, and $\mathrm{pH} 5.0 \pm 0.1$. 


\subsubsection{Effect of Initial Nickel Concentration}

The effect of initial nickel concentration was examined by varying the initial nickel ion concentration from $250 \mathrm{mg} / \mathrm{L}, 500 \mathrm{mg} / \mathrm{L}$ and $1000 \mathrm{mg} / \mathrm{L}$ and keeping all other conditions unchanged. The results in Figure 5.3 show that nickel adsorption reached equilibrium within 100 minutes. It is inappropriate to comment on the rate of adsorption as this experiment is missing initial data points at the lower concentrations. However, an increase in initial nickel ion concentration from $250 \mathrm{mg} / \mathrm{L}$ to $1000 \mathrm{mg} / \mathrm{L}$ increased nickel uptake.

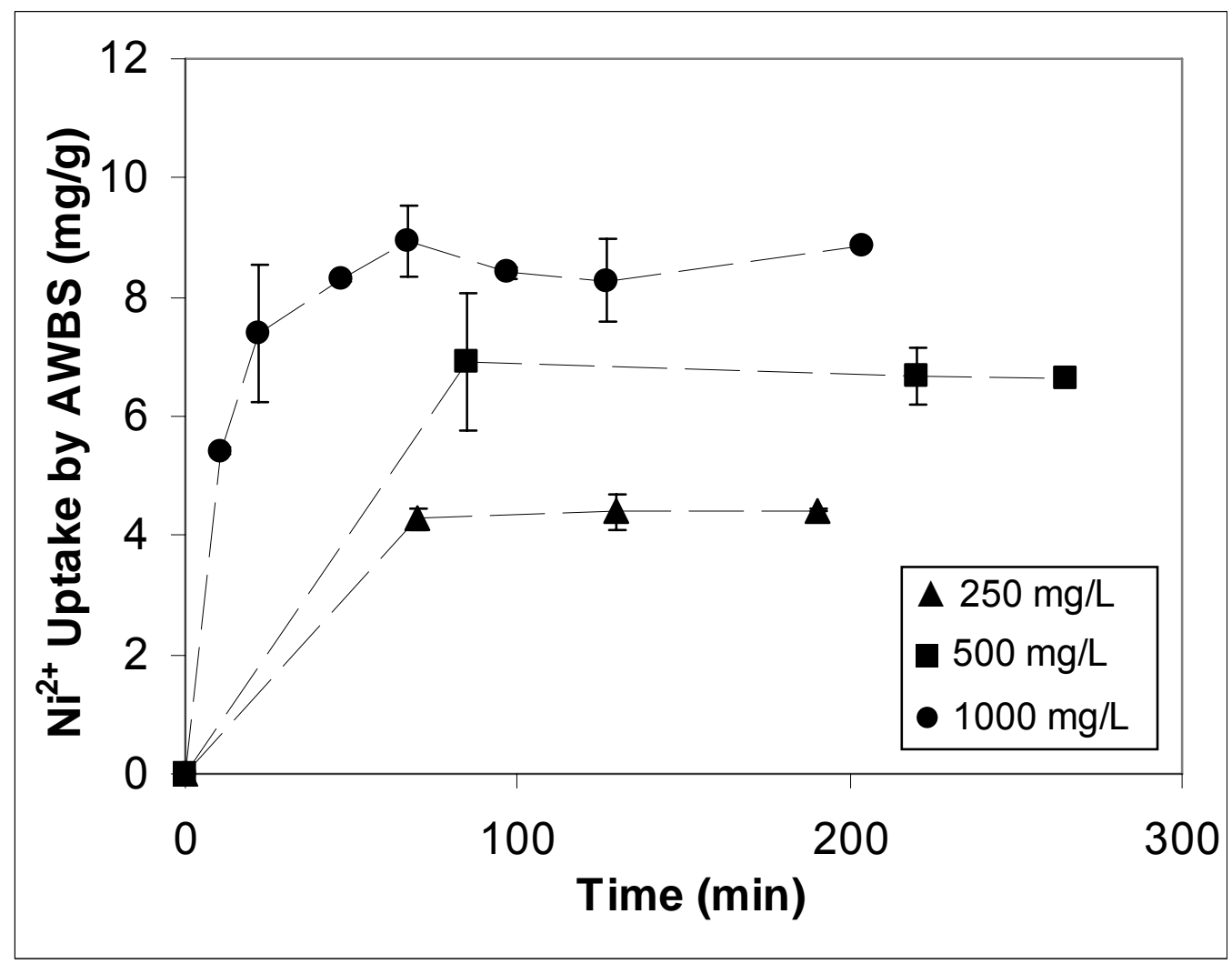

Figure 5.3: Effect of Initial Nickel Concentration

$250 \mathrm{~mL}$ initial $\mathrm{Ni}^{2+}$ solution, $2 \mathrm{~g}$ AWBS, particle size of $0.425-1.18 \mathrm{~mm}, 23 \pm 1^{\circ} \mathrm{C}$, and $\mathrm{pH} 5.0 \pm 0.1$. 


\subsubsection{Effect of $\mathrm{pH}$}

Solution $\mathrm{pH}$ affects the charge state of AWBS and the metal speciation. The effect of $\mathrm{pH}$ on nickel adsorption was examined by keeping the same initial nickel concentration, the amount of barley straw and varying the $\mathrm{pH}$ from 3 to 7 . There was no nickel adsorption occurring at $\mathrm{pH}$ 3. The results in Figure 5.4 show that nickel adsorption reached equilibrium within 60 70 minutes; increase in $\mathrm{pH}$ from 5 to 7 did not show any significant change in the time to reach equilibrium. However, with increase in $\mathrm{pH}$, nickel uptake by barley straw was increased in the tested $\mathrm{pH}$ range; this is because the PZNC is about $\mathrm{pH}$ 4.4, when the $\mathrm{pH}$ is increased from 5 to 7 more negatively charged sites are available for nickel binding hence the increased uptake.

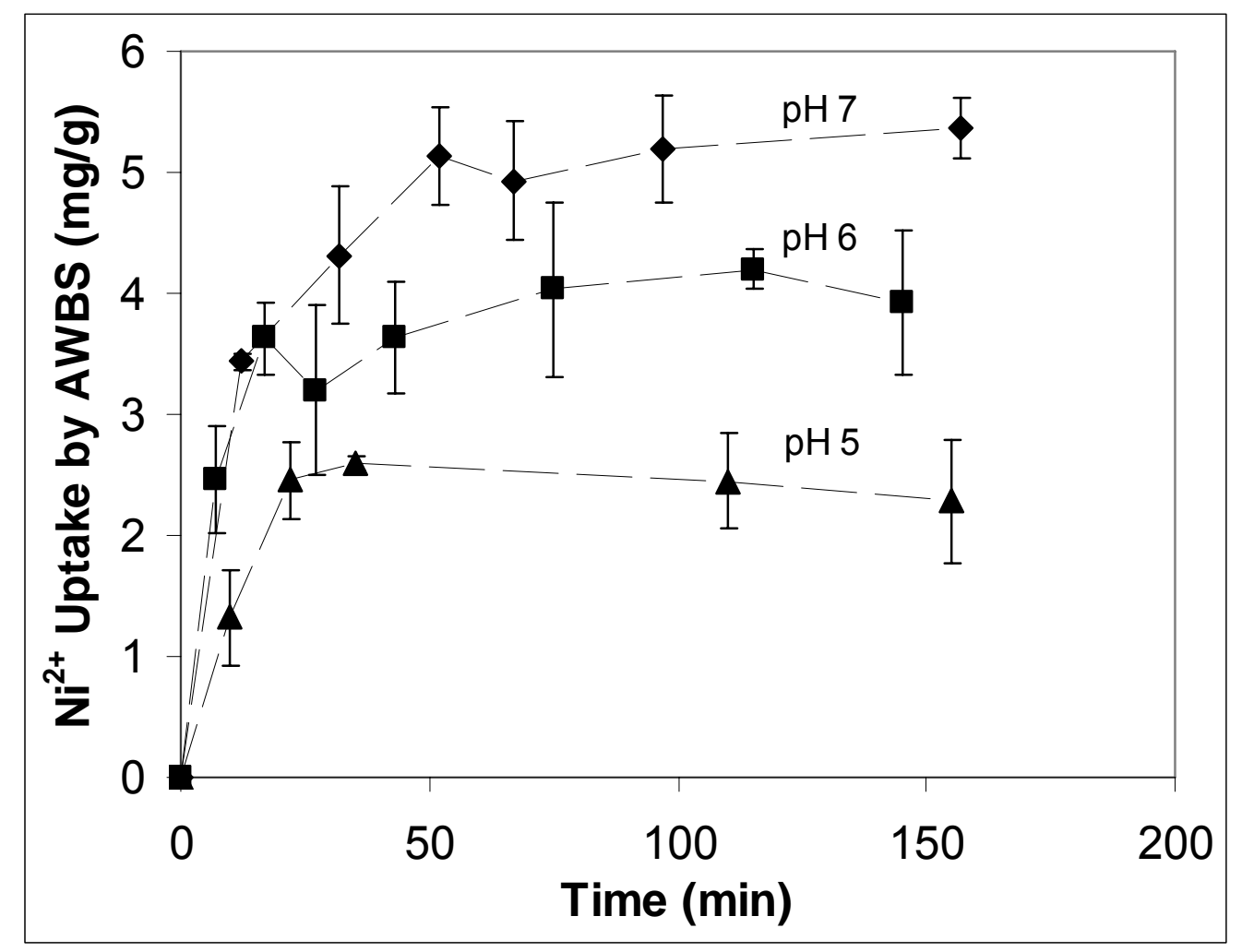

Figure 5.4: Effect of pH on Nickel Adsorption Kinetics

$250 \mathrm{~mL}$ of $83 \pm 3 \mathrm{mg} / \mathrm{L}$ initial Ni solution at $23 \pm 1^{\circ} \mathrm{C}, 2 \mathrm{~g}$ AWBS, particle size of $0.425-1.18 \mathrm{~mm}$. 


\subsubsection{Effect of Temperature}

The effect of temperature on nickel adsorption kinetics was studied using high initial nickel ion concentration ( $1000 \mathrm{mg} / \mathrm{L})$ solutions and the results are shown in Figure 5.5. It is observed that the time required to reach equilibrium was not significantly affected while increasing the temperature from $5^{\circ} \mathrm{C}$ to $40^{\circ} \mathrm{C}$. However, nickel uptake by barley straw was significantly reduced whilst the temperature was increased from $23^{\circ} \mathrm{C}$ to $40^{\circ} \mathrm{C}$; this indicates that the adsorption process is exothermic.

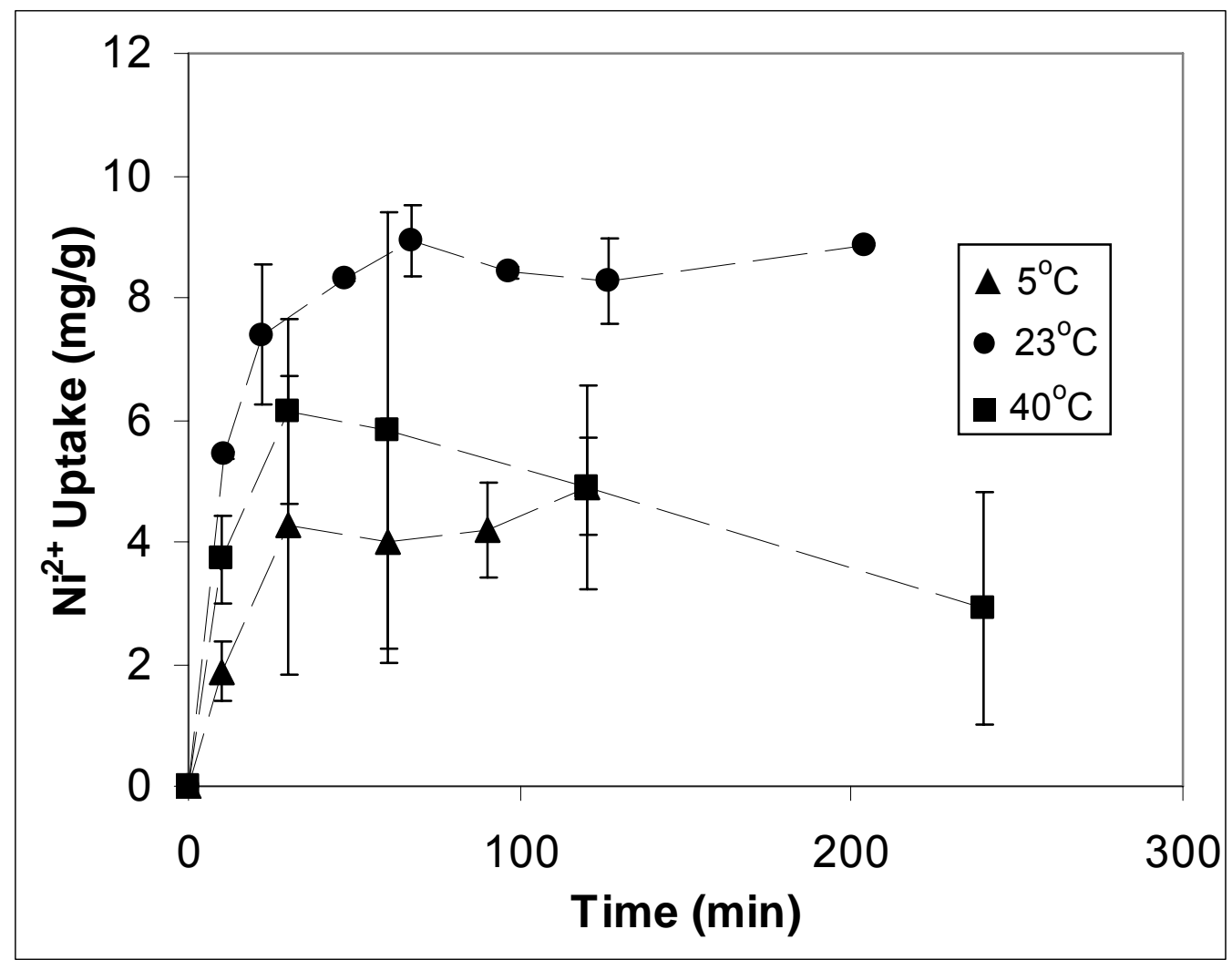

Figure 5.5: Effect of Temperature on Kinetics

$250 \mathrm{ml}$ of $977 \pm 18 \mathrm{mg} / \mathrm{L}$ initial Ni solution, $2 \mathrm{~g}$ AWBS particle size of $0.425-1.18$ $\mathrm{mm}, \mathrm{pH} 5.0 \pm 0.1$. 
It is also observed from Figure 5.5 for a low temperature $\left(5^{\circ} \mathrm{C}\right)$ nickel uptake was low. The esters present in barley straw biomass may resist the hydration of biomass, hence, resulting in low nickel uptake. At $5^{\circ} \mathrm{C}$, more time was required for the proper mixing of biomass and nickel solution than at the higher temperatures; this may be due to the higher surface tension of water at low temperatures. At high temperature $\left(40^{\circ} \mathrm{C}\right)$ nickel uptake was decreased after about 100 minutes, this may be due to the exothermic adsorption. This phenomenon is similar to that reported for nickel biosorption by Saccharomyces cerevisiae which showed increase in uptake when the temperature was raised from $15^{\circ} \mathrm{C}$ and the maximum uptake was attained at $25^{\circ} \mathrm{C}$ and the uptake decreased when the temperature was raised from $25^{\circ} \mathrm{C}$ to $40^{\circ} \mathrm{C}$ (Ozer 2003).

\subsubsection{Mass Transfer Modeling}

Biosorption is a process in which the rate of adsorption is largely controlled by mass transfer between the bulk fluid and the type of sorbents (Volesky 2003). Mass transfer modeling has been performed based on the assumption that the external mass transfer is the rate limiting step for the nickel ion and AWBS system (Loukidou et al. 2004; Koumanova et al. 2002; Puranik et al. 1999). In this work, the volumetric mass transfer coefficients $K_{L} a(1 / \mathrm{min})$ were obtained by fitting the experimental data to Equation 2.4 with the aid of sigma plot software. The mass transfer models and parameters are shown in Figures 5.6, 5.7, 5.8 and Tables 5.3, 5.4 and 5.5.

Figure 5.6 shows the effect of particle size on nickel ion adsorption by AWBS. The model fits well the nickel adsorption data with the relative errors from $1.0 \%$ to $5.1 \%$. It is 
observed that the volumetric mass transfer coefficient $\left(K_{L} a\right)$ was increased from $0.060 \pm 0.016 \mathrm{~min}^{-1}$ to $0.151 \pm 0.018 \mathrm{~min}^{-1}$ (Table 5.3) when the AWBS particles were decreased from 1.18-3.35 mm to less than $0.425 \mathrm{~mm}$; the $K_{L} a$ was the same magnitude as that reported (0.03 to $0.1 \mathrm{~min}^{-1}$ ) by Puranik et al. (1999). This indicates that the smaller particle size have higher surface area and mass transfer coefficient, and hence, lower external mass transfer resistance.

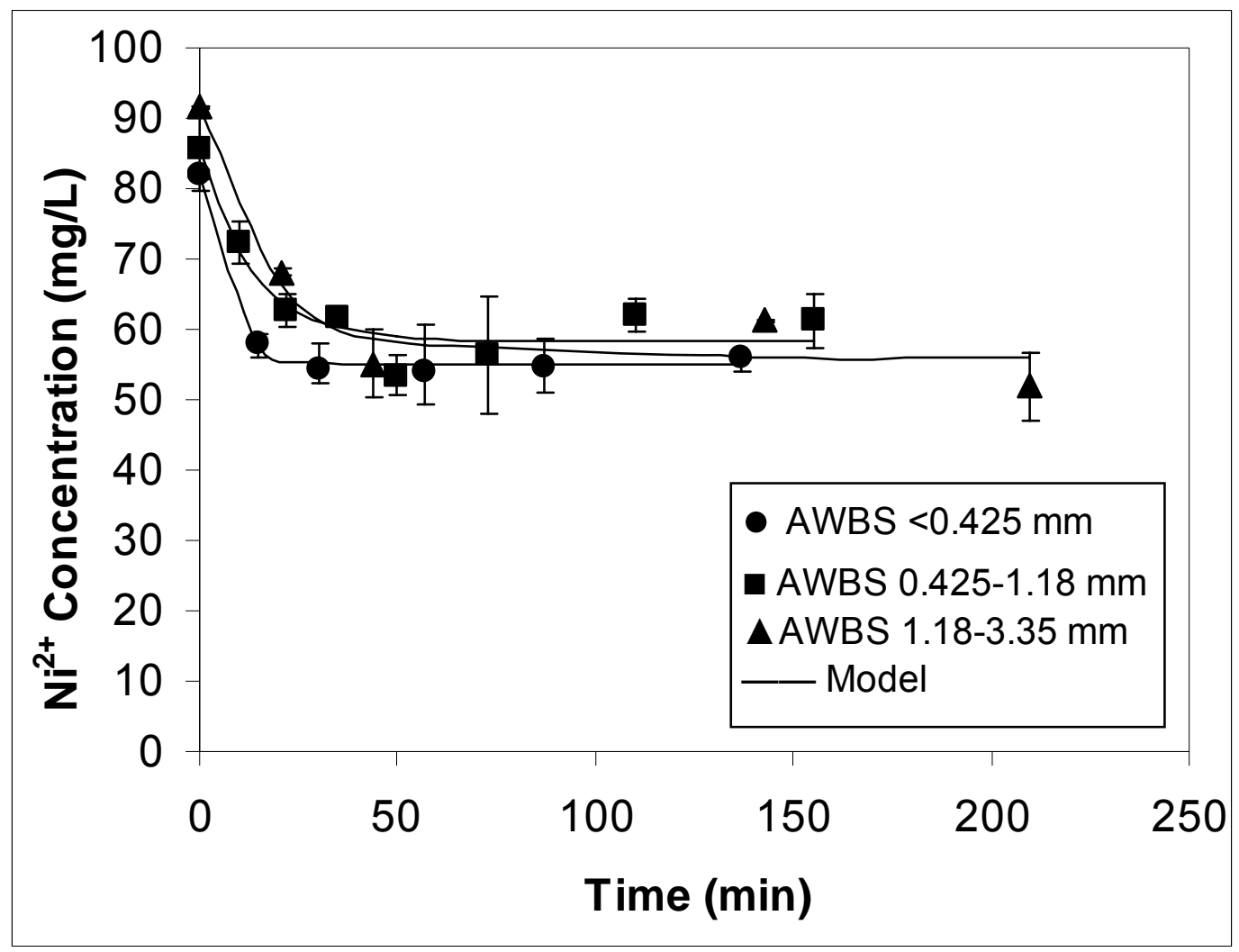

Figure 5.6: Modeling the Effect of Particle Size on Nickel Adsorption Kinetics

$250 \mathrm{~mL}$ of $87 \pm 5 \mathrm{mg} / \mathrm{L}$ initial Ni solution, $2 \mathrm{~g}$ of AWBS, particles size of $0.425-1.18$ $\mathrm{mm}, 23 \pm 1^{\circ} \mathrm{C}$, and $\mathrm{pH} 5.0 \pm 0.1$. 
Table 5.3: Model Parameters: Effect of Particle Size on Nickel Adsorption Kinetics

\begin{tabular}{|c|c|c|c|}
\hline $\begin{array}{c}\text { AWBS particle size } \\
\text { (mm) }\end{array}$ & $\begin{array}{c}\text { Volumetric mass transfer } \\
\text { coefficient }\left(\mathrm{min}^{-1}\right)\end{array}$ & $\mathbf{r}^{2}$ & $\begin{array}{c}\text { Relative error } \\
(\%)\end{array}$ \\
\hline 1.18-3.35 & $0.060 \pm 0.016$ & 0.9400 & 5.1 \\
\hline $0.425-1.18$ & $0.076 \pm 0.016$ & 0.9162 & 3.7 \\
\hline$<0.425$ & $0.151 \pm 0.018$ & 0.9953 & 1.0 \\
\hline
\end{tabular}

Figure 5.7 shows the effect of $\mathrm{pH}$ on nickel adsorption kinetics. The model fits well with the data points with the relative errors from $1.3 \%$ to $3.1 \%$ (Table 5.4 ). The volumetric mass transfer coefficient $\left(K_{L} a\right)$ increased from $0.099 \pm 0.011 \mathrm{~min}^{-1}$ to $0.133 \pm 0.021 \mathrm{~min}^{-1}$ while increasing $\mathrm{pH}$ from 5 to 6 , where a further increase in $\mathrm{pH}$ decreases the mass transfer coefficient. The reason for $K_{L} a$ decrease at $\mathrm{pH} 7$ is not known. However, the values of $K_{L} a$ were in the same magnitude to that reported (0.03 to $0.1 \mathrm{~min}^{-}$ ${ }^{1}$ ) by Puranik et al. (1999). In addition, nickel uptake was higher at pH values of 6 and 7, and indicates that at the higher $\mathrm{pH}$ AWBS possesses more anionic charge and favors higher adsorption uptake. 


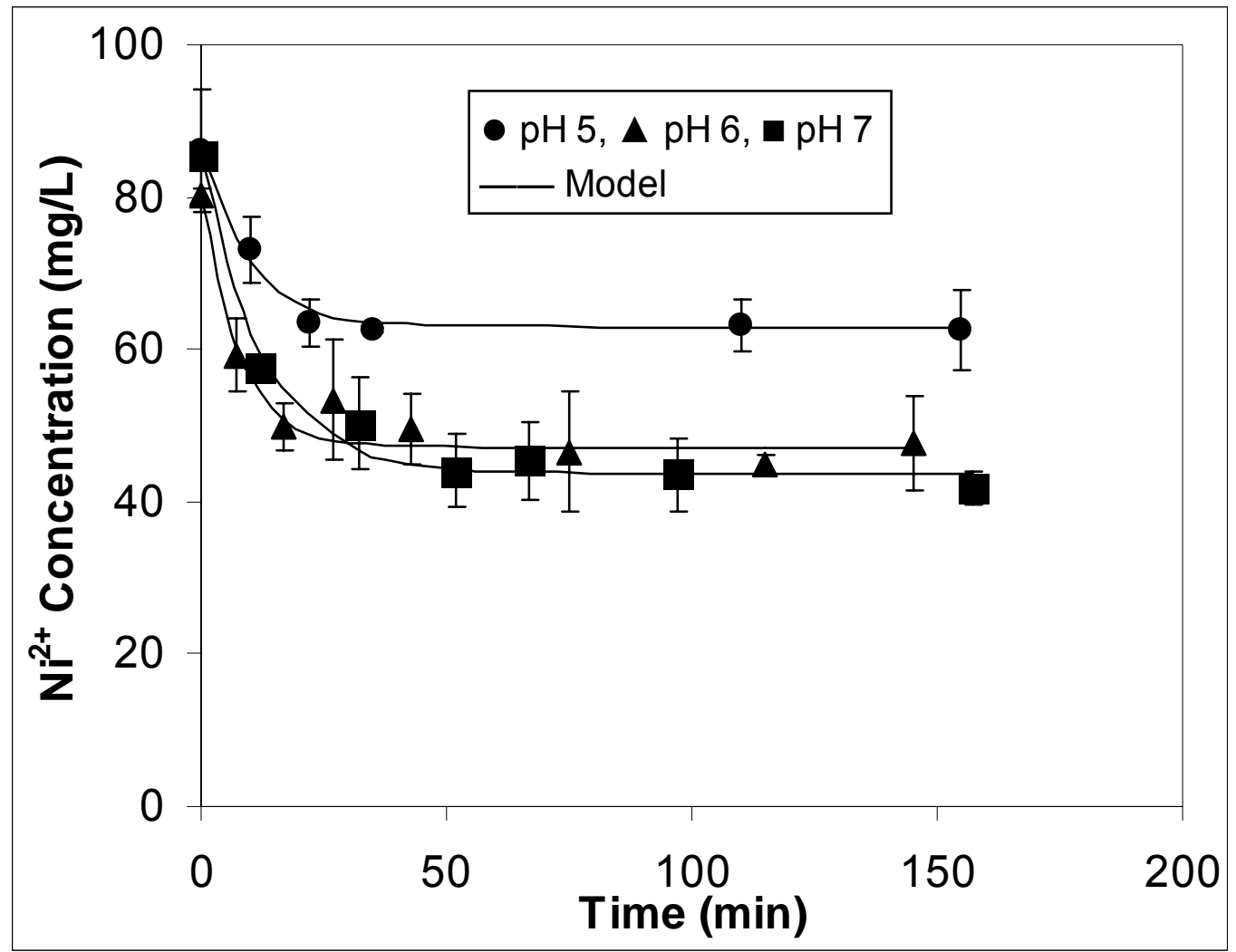

Figure 5.7: Modeling the Effect of $\mathrm{pH}$ on Nickel Adsorption Kinetics

$250 \mathrm{~mL}$ of $83 \pm 3 \mathrm{mg} / \mathrm{L}$ initial Ni solution at $23 \pm 1^{\circ} \mathrm{C}, 2 \mathrm{~g}$ AWBS, particle size of 0.425-1.18 mm.

Table 5.4: Model Parameters: Effect of $\mathrm{pH}$ on Nickel Adsorption Kinetics

\begin{tabular}{cccc}
\hline $\mathbf{p H}$ & Volumetric mass transfer coefficient $\left(\mathrm{min}^{-\mathbf{1}}\right)$ & $\mathbf{r}^{2}$ & Relative error (\%) \\
\hline $5.0 \pm 0.1$ & $0.099 \pm 0.011$ & 0.9837 & 1.3 \\
& & & \\
$6.0 \pm 0.1$ & $0.133 \pm 0.021$ & 0.9578 & 3.1 \\
& & & \\
$7.0 \pm 0.1$ & $0.082 \pm 0.009$ & 0.9845 & 2.7 \\
\hline
\end{tabular}


Figure 5.8 show the effect of temperature on nickel adsorption kinetics. The model exhibited reasonable fit to the data with the relative errors from $0.2 \%$ to $0.4 \%$. The mass transfer coefficients (listed in Table 5.5) increased from $0.070 \pm 0.010 \mathrm{~min}^{-1}$ to $0.112 \pm 0.011$ $\min ^{-1}$ while increasing the temperature from $5^{\circ} \mathrm{C}$ to $40^{\circ} \mathrm{C}$. This indicates that the mass transfer resistance is low at high temperature.

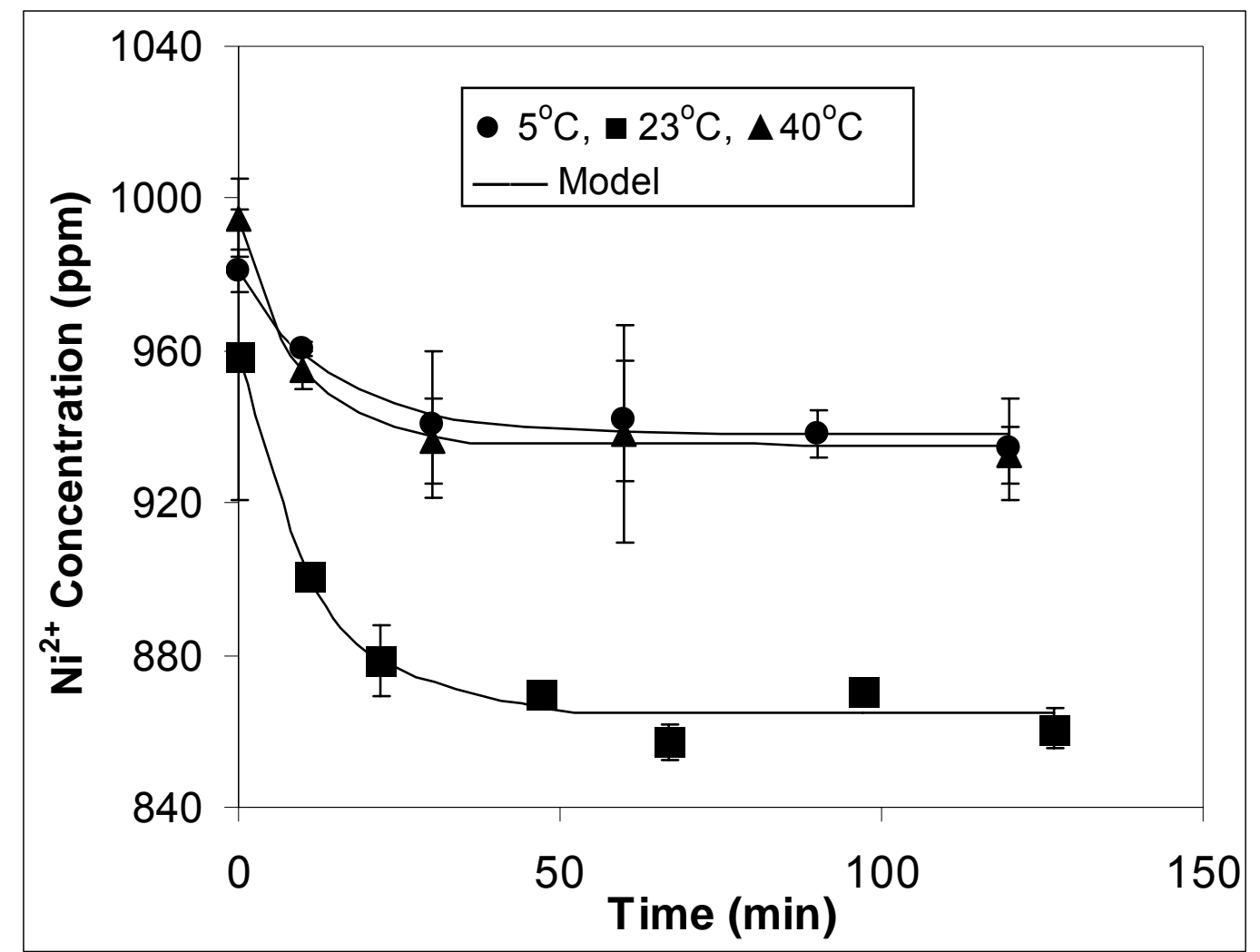

Figure 5.8: Modeling the Effect of Temperature on Nickel Adsorption Kinetics

$250 \mathrm{ml}$ of $977 \pm 18 \mathrm{mg} / \mathrm{L}$ initial $\mathrm{Ni}$ solution, $2 \mathrm{~g}$ AWBS $0.425-1.18 \mathrm{~mm}$, pH5.0 0.1.

It is observed that the higher uptake was achieved at $23^{\circ} \mathrm{C}$ than $40^{\circ} \mathrm{C}$; and indicates that nickel adsorption by AWBS is exothermic. The results also indicate that at room temperature $\left(23^{\circ} \mathrm{C}\right)$, the external mass transfer resistance is moderate and therefore better 
adsorption rate was achieved. At $5^{\circ} \mathrm{C}$, the biomass water contact angle is high, hence the biomass is hydrophobic in nature, thereby hydration processes are limited, and hence, the lower adsorption rate and uptake (Wisniewska et al. 2003). This phenomenon is similar to that reported for nickel biosorption by Saccharomyces cerevisiae which showed higher adsorption rate and uptake at $25^{\circ} \mathrm{C}$ than at lower $\left(15^{\circ} \mathrm{C}\right)$ and a higher $\left(40^{\circ} \mathrm{C}\right)$ temperature (Ozer 2003).

Table 5.5: Model Parameters: Effect of Temperature on Nickel Adsorption Kinetics

\begin{tabular}{|c|c|c|c|}
\hline $\begin{array}{c}\text { Temperature } \\
\left({ }^{\circ} \mathrm{C}\right)\end{array}$ & $\begin{array}{c}\text { Volumetric mass transfer } \\
\text { coefficient }\left(\mathrm{min}^{-1}\right)\end{array}$ & $\mathbf{r}^{2}$ & $\begin{array}{c}\text { Relative error } \\
(\%)\end{array}$ \\
\hline $5 \pm 1$ & $0.070 \pm 0.010$ & 0.9799 & 0.2 \\
\hline $23 \pm 1$ & $0.086 \pm 0.009$ & 0.9837 & 0.4 \\
\hline $40 \pm 1$ & $0.112 \pm 0.011$ & 0.9932 & 0.2 \\
\hline
\end{tabular}

\subsection{Equilibrium}

\subsubsection{Effect of Ionic Strength}

The effect of ionic strength on the nickel adsorption by barley straw was studied by adding $0.2 \mathrm{M}$ of sodium sulfate to the biosorption solutions and the $\mathrm{pH}$ was maintained to be 5.0 \pm 0.1 . The results are illustrated in Figure 5.9. 


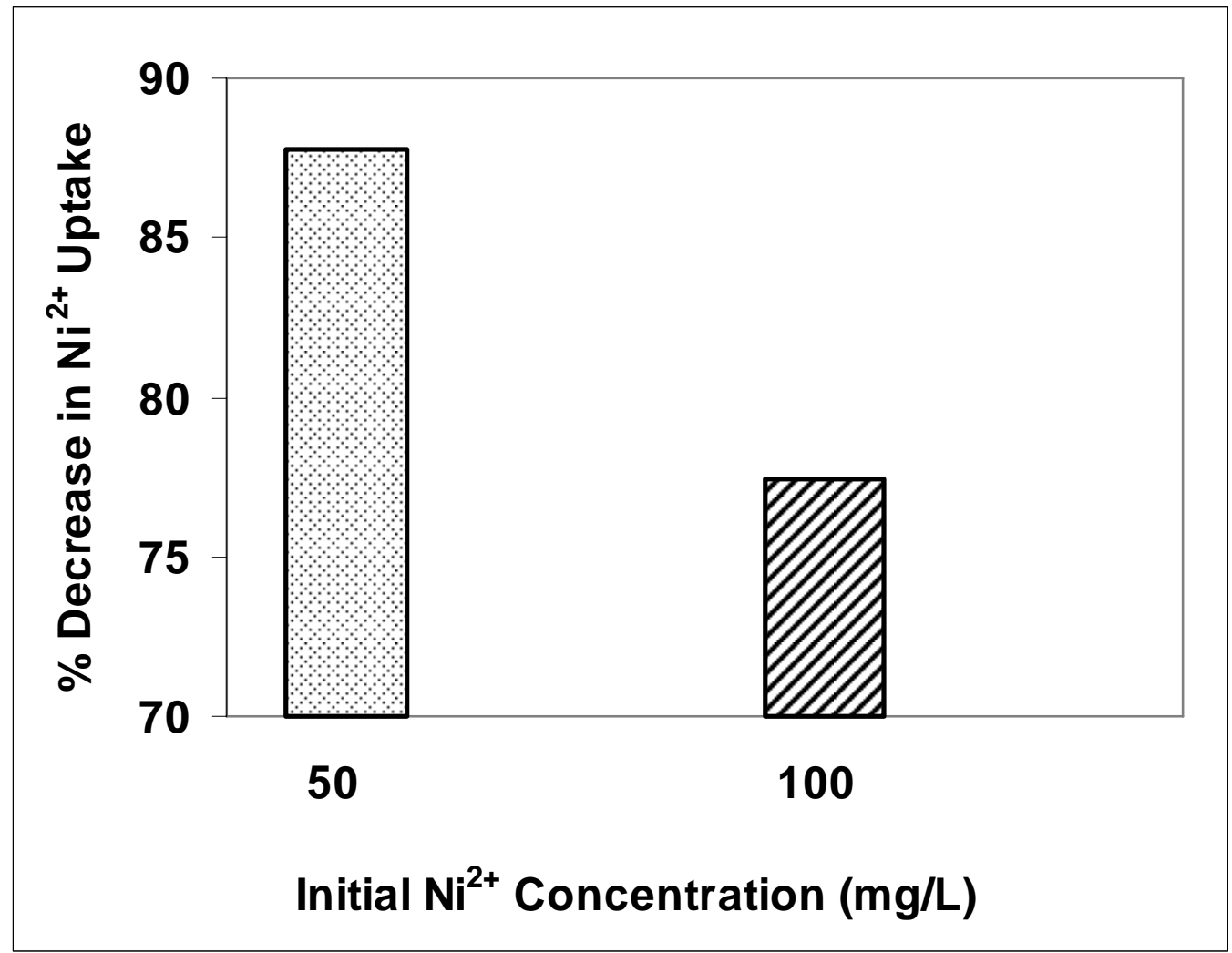

Figure 5.9: Effect of Ionic Strength on Nickel Uptake

2g AWBS $1.18 \mathrm{~mm}-3.35 \mathrm{~mm}, 0.2 \mathrm{M}$ sodium sulfate, $\mathrm{pH}=5.0 \pm 0.1,23 \pm 1^{\circ} \mathrm{C}, 2 \mathrm{~h}$.

At $\mathrm{pH}$ 5.0 \pm 0.1 , an increase in ionic strength from less than $0.02 \mathrm{M}$ (no ionic strength control) to around $0.2 \mathrm{M}$ significantly affected the nickel uptake. In the case of about $50 \mathrm{mg} / \mathrm{L}$ initial nickel concentration, the uptake was reduced by $88 \%$ and at about $100 \mathrm{mg} / \mathrm{L}$ initial nickel concentration the equilibrium uptake was reduced by $77 \%$. The results are similar to that reported for biosorption of selenium and gold by acid washed crab shells. The equilibrium uptake was reduced to about $75 \%$ with the increase in ionic strength from no ionic strength control to around $0.1 \mathrm{M} \mathrm{NaCl}$ (Niu 2003). 


\subsubsection{Effect of Particle Size}

The effect of particle size of barley straw on equilibrium nickel ion uptake was examined by varying particle sizes from less than $0.425 \mathrm{~mm}$ to $1.18-3.35 \mathrm{~mm}$. The results shown in Figure 5.10 demonstrate that the equilibrium nickel uptake by barley straw was slightly increased when the particle size of the straw was decreased, and a maximum uptake was achieved when the particle size was less than $0.425 \mathrm{~mm}$. This phenomenon is similar to that reported by Pamukoglu and Kargi on copper (II) adsorption by powdered waste sludge, the uptake was increased from $26 \mathrm{mg} / \mathrm{g}$ to $121 \mathrm{mg} / \mathrm{g}$ when the particle size decreased from 231 to $53 \mu \mathrm{m}$; Volesky also reported similar observations. They explained that smaller biosorbent particles have higher surface area, more binding sites are available for the metal ions and hence higher uptake (Pamukoglu and Kargi 2007; Volesky 2003). This was also confirmed by Oraedu and Niu (2008), the surface area increased from 0.9 $\mathrm{m}^{2} / \mathrm{g}$ to $2.4 \mathrm{~m}^{2} / \mathrm{g}$ when the barley straw particle size decreased from $1.18-3.35 \mathrm{~mm}$ to less than $0.425 \mathrm{~mm}$. However if the size of biosorbent particles is too small, the separation of biosorbents from the liquid phase becomes more difficult. Thus, for better control of experiments, a medium size sorbent with better uptake $(0.425-1.18 \mathrm{~mm})$ was selected for further studies. 


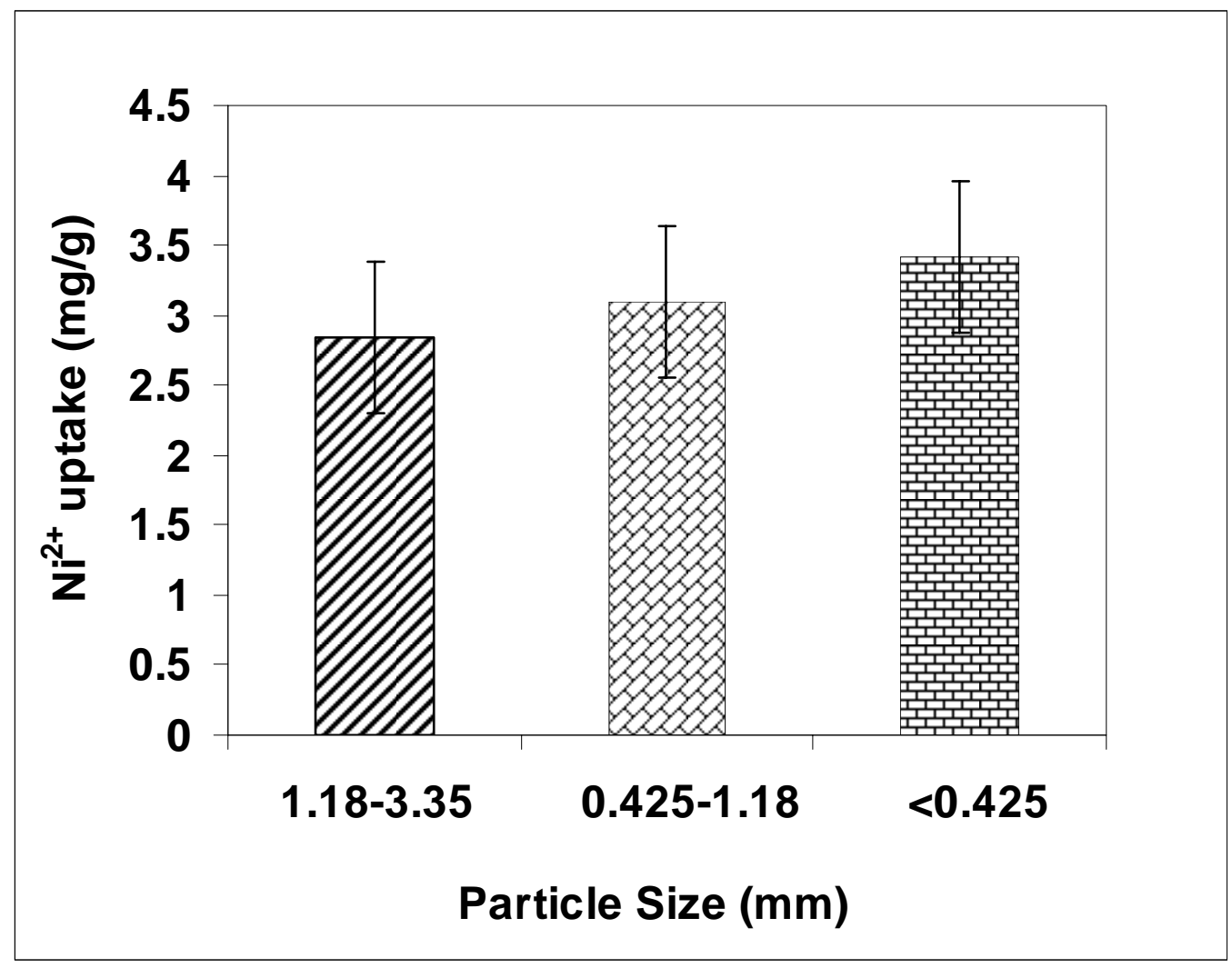

Figure 5.10: Effect of Particle Size on Nickel Uptake by Barley Straw

Initial Ni concentration $87 \pm 5 \mathrm{mg} / \mathrm{L}, \mathrm{pH} 5.0 \pm 0.1,23 \pm 1^{\circ} \mathrm{C}$, and $2 \mathrm{~h}$.

\subsubsection{Effect of pH on Nickel Adsorption Isotherms}

The effect of $\mathrm{pH}$ on nickel adsorption isotherms was examined by varying the solution $\mathrm{pH}$ and initial nickel ion concentration. The results were shown in Figure 5.11. Nickel ion uptakes at equilibrium were plotted against the equilibrium nickel concentrations at $\mathrm{pH} 5.00 \pm 0.12$ and $\mathrm{pH} 7.41 \pm 0.12$. It is observed that at low equilibrium nickel concentrations, an increase in $\mathrm{pH}$ significantly increased the nickel uptake in the tested range. However, at high equilibrium nickel concentrations, nickel ions $\left(\mathrm{Ni}^{2+}\right)$ have enough driving force to replace protons in the binding sites, and hence, there was no 
significant change in uptake with the increase of equilibrium $\mathrm{pH}$ from $\mathrm{pH} 5.00 \pm 0.12$ to $\mathrm{pH}$ $7.41 \pm 0.12$.

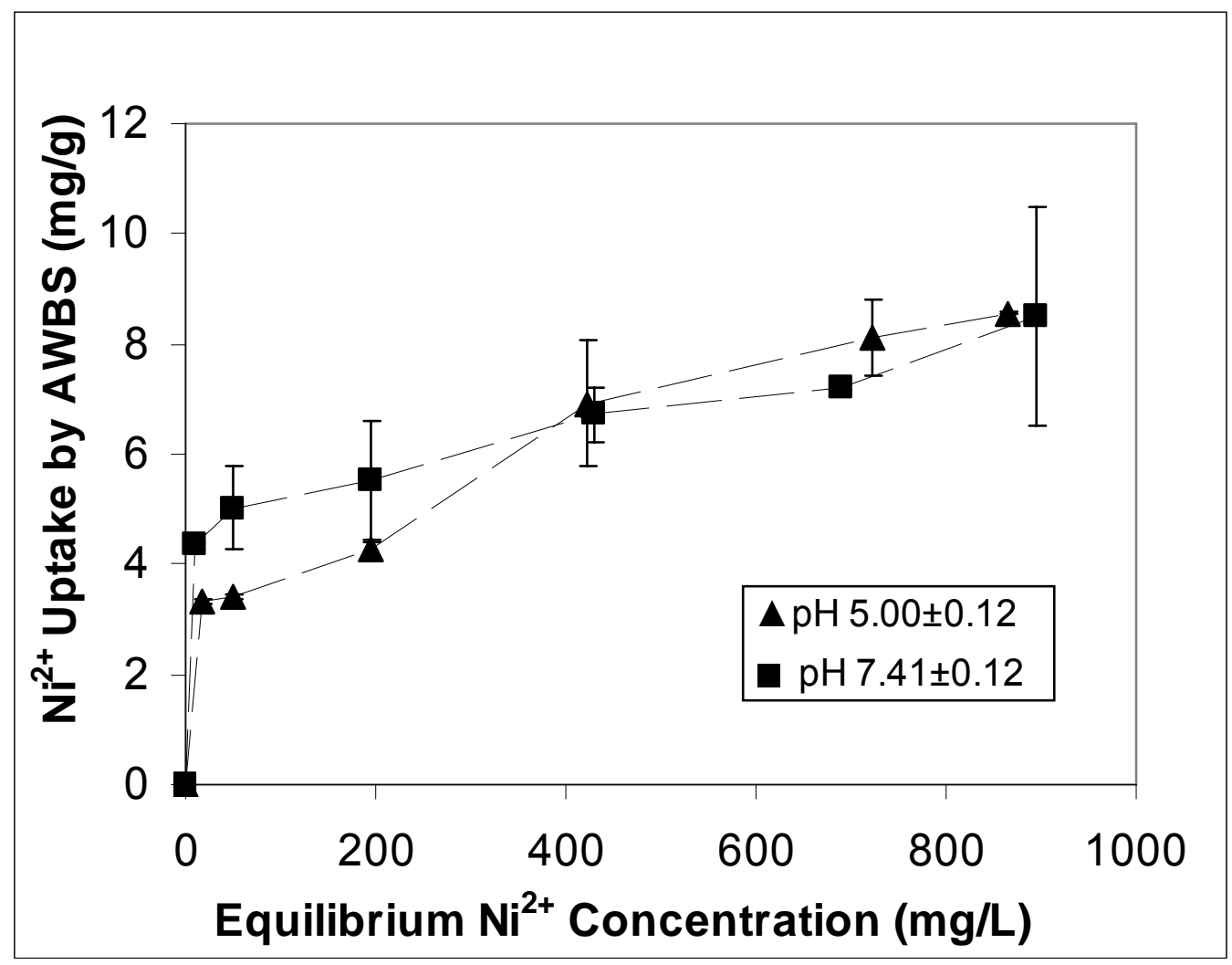

Figure 5.11: Effect of $\mathrm{pH}$ on Nickel Adsorption Isotherms

$250 \mathrm{~mL}$ initial Ni solution at $23 \pm 1^{\circ} \mathrm{C}, 2 \mathrm{~g}$ AWBS, particle size of $0.425-1.18 \mathrm{~mm}$, and $2 \mathrm{~h}$.

An equilibrium nickel concentration range of lower than $400 \mathrm{mg} / \mathrm{L}$, and an increase of $\mathrm{pH}$ increased the equilibrium nickel uptake. This was further illustrated by investigating nickel adsorption by varying $\mathrm{pH}$ from 5 to 8 ; Figure 5.12 shows the results. Each sample had $250.0 \pm 0.2 \mathrm{~mL}$ solution containing $87 \pm 5 \mathrm{mg} / \mathrm{L}$ initial nickel concentration and $2.00 \mathrm{~g}$ AWBS. As $\mathrm{pH}$ was increased from $5.0 \pm 0.1$ to $8.0 \pm 0.1$, the nickel uptake was also increased. 


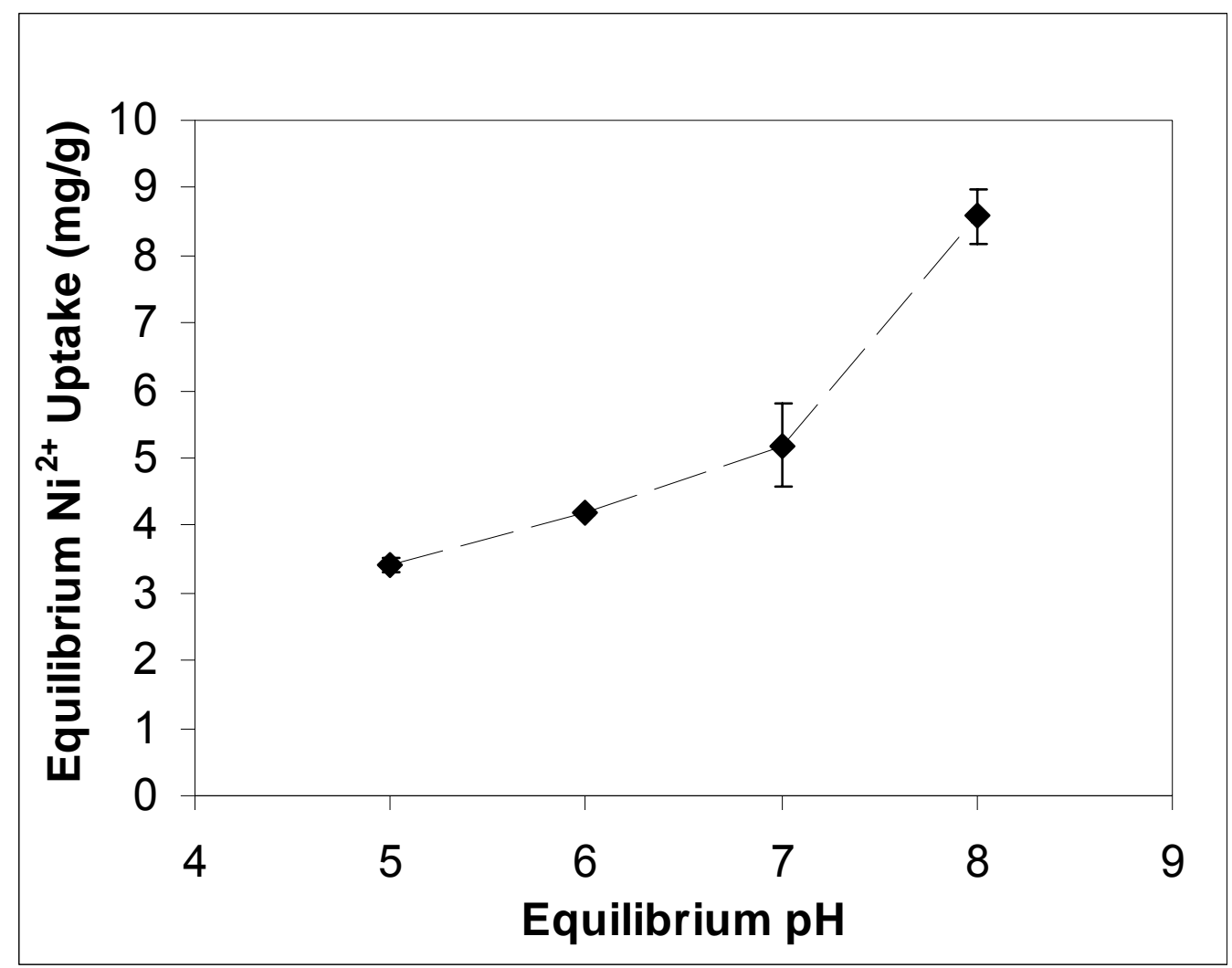

Figure 5.12: Effect of pH on Nickel Uptake

$250 \mathrm{~mL}$ of $87 \pm 5 \mathrm{mg} / \mathrm{L}$ initial Ni solution, $2 \mathrm{~g}$ AWBS, particle size of $0.425-$ $1.18 \mathrm{~mm}, 23 \pm 1^{\circ} \mathrm{C}$, and $2 \mathrm{~h}$.

In barley straw, hemi-cellulose, cellulose, lignin and protein contain carboxyl and amide groups and these groups are capable of adsorbing metal ions (Ahalya 2005; Lee 2004; Roberts 1992). The logarithm of proton dissociation constants (pK) of carboxyl group and conjugated amide $\left(\mathrm{NH}_{2}{ }^{+}\right)$are 3.5-4.5 (Buffle 1988; Roberts 1992). The PZNC of AWBS is about 4.4, the solution $\mathrm{pH}$ has to be higher than 4.4 so that the protons are effectively dissociated and the functional groups are with negative charge and capable of binding nickel ions. However, the higher the $\mathrm{pH}$, the more the hydroxide ions present in the solution which could cause nickel ion precipitation. 


\subsubsection{Effect of pH on Nickel Precipitation}

In order to verify the possibility of the precipitation of nickel under experimental conditions, precipitation of nickel was examined by a series of solutions of varying $\mathrm{pH}$ from 5 to 10. The results are illustrated in Figure 5.13. At pH values up to 8, there was no obvious nickel ion precipitation observed. When the $\mathrm{pH}$ was increased to $8.5,40 \%$ of the ions precipitated. Approximately $95 \%$ of nickel was precipitated when the solution $\mathrm{pH}$ was raised to 9.2, and further, complete precipitation occurred at $\mathrm{pH}$ 10.0. These results are quite comparable with that of theoretical values (Dean 1999). There is little evidence of precipitation at $\mathrm{pH}$ of $3 \sim 8$, when the initial nickel concentration is $87 \pm 5 \mathrm{mg} / \mathrm{L}$.

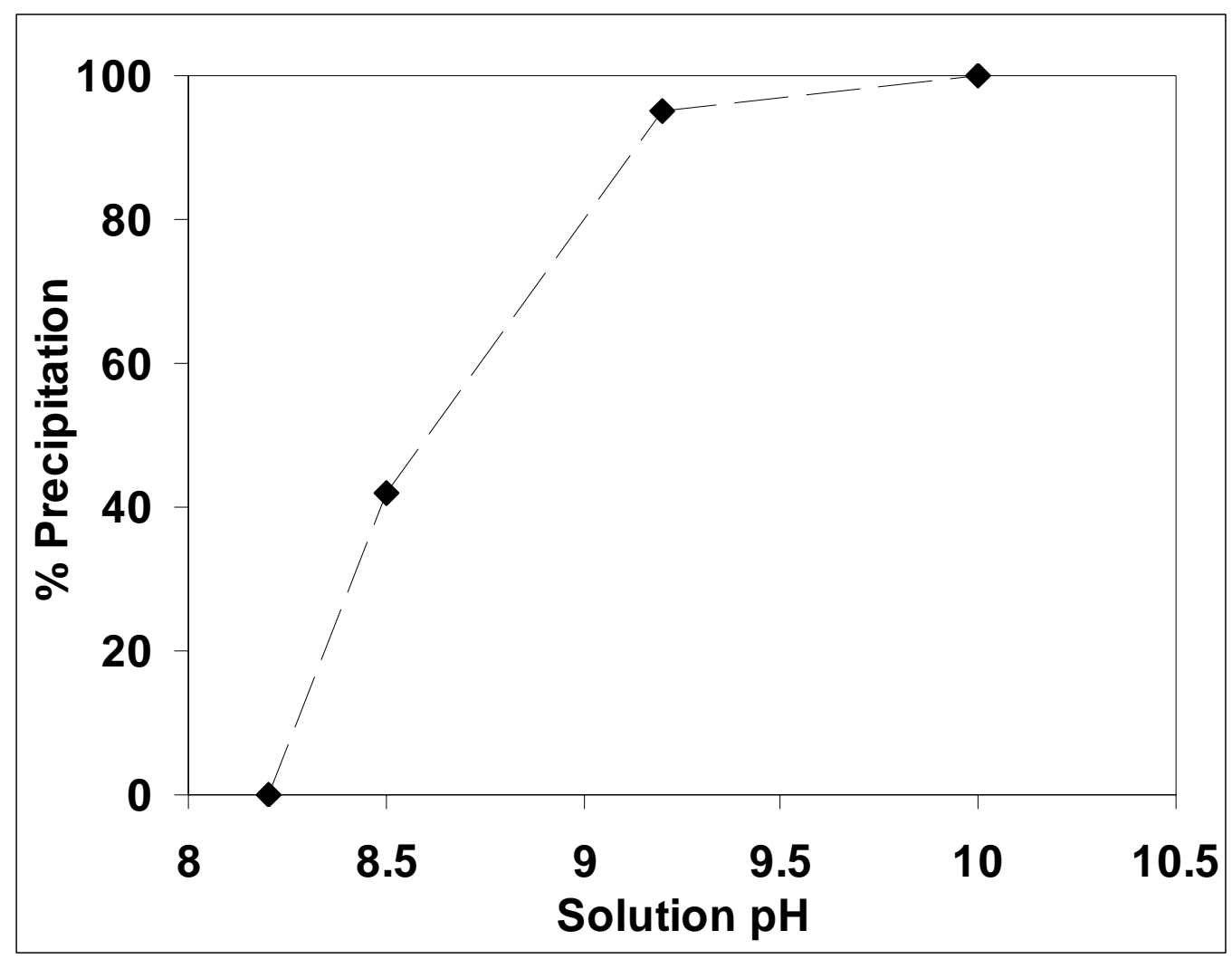

Figure 5.13: Effect of $\mathrm{pH}$ on Nickel Precipitation $250 \mathrm{~mL}, 87 \pm 5 \mathrm{mg} / \mathrm{L}$ initial Ni solution, $23 \pm 1^{\circ} \mathrm{C}$, and $24 \mathrm{~h}$. 


\subsubsection{Effect of Temperature on Nickel Adsorption Isotherms}

The effect of temperature on nickel uptake was studied at three different temperatures, $5^{\circ} \mathrm{C}, 23^{\circ} \mathrm{C}$ and $40^{\circ} \mathrm{C}$. The results presented in Figure 5.14 show the isotherms at the above mentioned temperatures. The maximum uptake of $8.45 \mathrm{mg} / \mathrm{g}$ is observed at $23^{\circ} \mathrm{C}$ with the initial nickel concentration of about $1000 \mathrm{mg} / \mathrm{L}$; whereas at $5^{\circ} \mathrm{C}$ and $40^{\circ} \mathrm{C}$ the equilibrium nickel uptake was significantly lower with the same initial concentration. Increase in the temperature from $23^{\circ} \mathrm{C}$ to $40^{\circ} \mathrm{C}$ resulted in a decreased equilibrium nickel uptake, which indicates that the adsorption may be exothermic.

Volesky (2003) pointed out that the extent of physical adsorption decreases rapidly with the increase of temperature; this indicates that physical adsorption may contribute to a greater extent in nickel adsorption by barley straw. If nickel adsorption by barley straw is exothermic, it should achieve better uptake at $5^{\circ} \mathrm{C}$, but achieved a lower uptake. At low temperature $\left(5^{\circ} \mathrm{C}\right)$, barley straw may become hydrophobic due to the presence of large amounts of waxes and esters (Naik et al. 2009; Wisniewska et al. 2003). As a result, the wetting (hydration process) of AWBS seemed to be inadequate and the mixing with nickel solution could not be performed as compared to that of higher temperatures.

The results demonstrated in Figure 5.14 shows better equilibrium nickel uptake at room temperature. Comparison of the determined nickel uptake from this work to that reported in literature is shown in Table 5.6. 


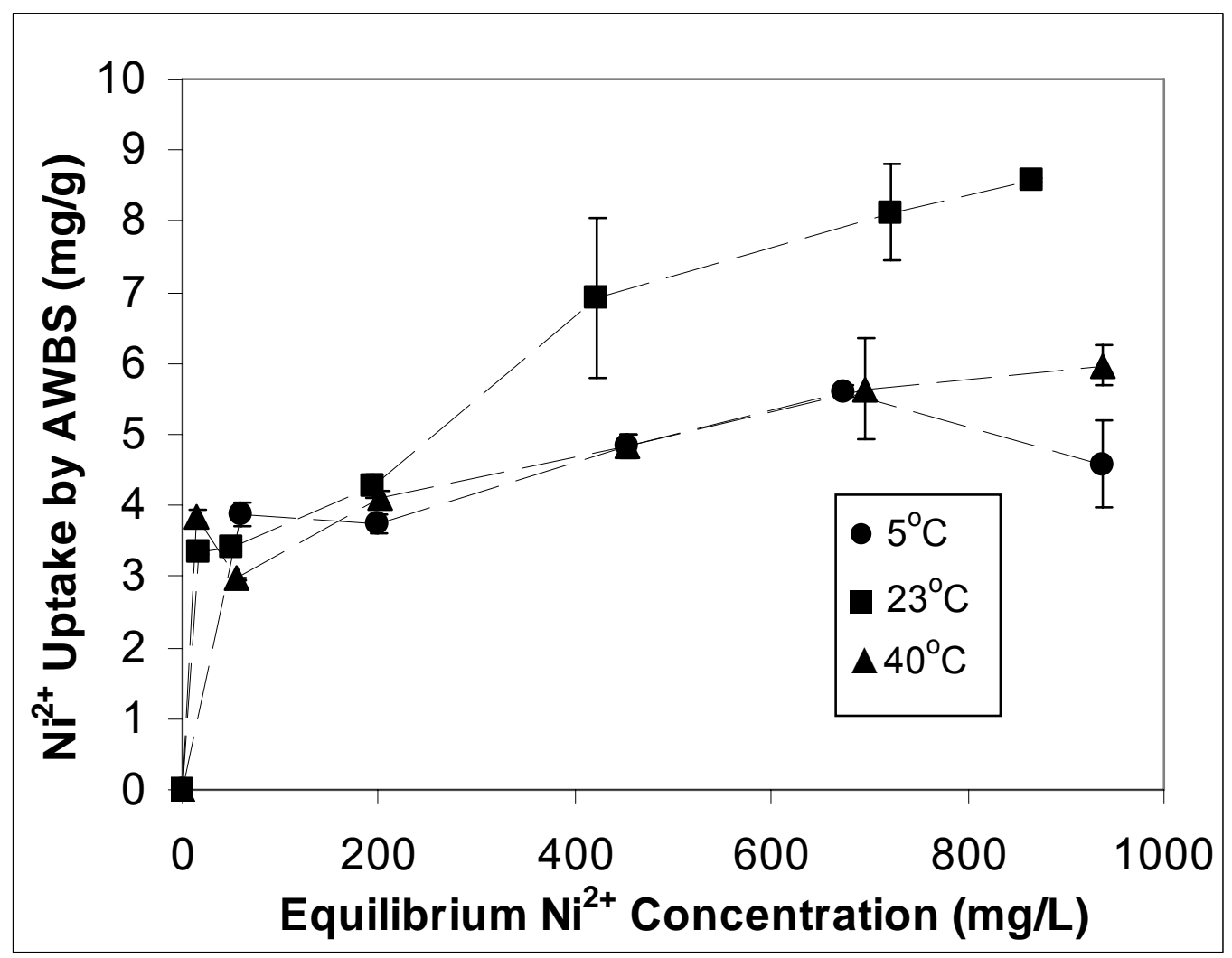

Figure 5.14: Effect of Temperature on Nickel Adsorption Isotherms $250 \mathrm{~mL}$ initial Ni solution, 2g AWBS and pH 5.0 \pm 0.1 .

The maximum nickel uptake of $8.5 \mathrm{mg} / \mathrm{g}$ from this work (Table 5.6) is comparable to that reported by Larsen and Schierup by barley straw (Larsen 1981). It is also slightly higher than that of rice husk (5.5 mg/g) and Brazil nut shells (7.9mg/g) (Krishnani 2008; Basso 2002). It is lower than orange peel $(75.2 \mathrm{mg} / \mathrm{g})$ and rice bran $(44.8 \mathrm{mg} / \mathrm{g})($ Hanif 2007; Zafar 2007). However, barley straw has the advantage to prohibit growth of algae and cyano-bacteria; in this regard, it shows potential for treating pond water and to protect environment. 
Table 5.6: Biosorbents Reported on Nickel Adsorption

\begin{tabular}{|c|c|c|c|}
\hline Biosorbent & $\begin{array}{l}\text { Max Ni } \\
\text { Uptake } \\
(\mathrm{mg} / \mathrm{g})\end{array}$ & pH & Reference \\
\hline Barley straw, untreated & 6.4 & $6.5 \pm 0.2$ & (Larsen 1981) \\
\hline $\begin{array}{c}\text { Barley straw, previously } \\
\text { washed with demineralised } \\
\text { water }\end{array}$ & 4.6 & $6.4 \pm 0.2$ & (Larsen 1981) \\
\hline Brazil nut shells, untreated & 7.9 & $5.8 \pm 0.1$ & (Basso 2002) \\
\hline $\begin{array}{l}\text { Rice bran, washed with } \\
\mathrm{HCl}, \mathrm{H}_{2} \mathrm{SO}_{4} \text { and } \mathrm{H}_{3} \mathrm{PO}_{4}\end{array}$ & 44.8 & $6.0 \pm 0.1$ & (Zafar 2007) \\
\hline Rice husk, alkali treated & 5.5 & $6.0 \pm 0.1$ & (Krishnani 2008) \\
\hline $\begin{array}{l}\text { Orange peel, washed with } \\
20 \% \text { Iso-propyl alcohol, } \\
\text { saponification with } \mathrm{NaOH} \\
\text { and modified with } \\
\text { phosphoric acid }\end{array}$ & 75.2 & $6.0 \pm 0.2$ & (Li 2008) \\
\hline $\begin{array}{c}\text { Barley straw, washed by } \\
1 \mathrm{~N} \mathrm{HCl}\end{array}$ & 8.5 & $5.0 \pm 0.1$ & This work \\
\hline
\end{tabular}

\subsubsection{Adsorption Isotherm Modeling}

The Freundlich and the Langmuir equations were considered for modeling the adsorption isotherms. Of the two, the Langmuir model exhibited a poor fit with an average relative error of up to $17 \%$, low $\mathrm{r}^{2}$ values and some of the parameters showing negative values; hence this model is not acceptable. The Freundlich isotherm model exhibited better fit with an average relative error less than $10 \%$ and acceptable $\mathrm{r}^{2}$ on both the $\mathrm{pH}$ and temperature isotherms. The simulated uptakes using the Freundlich equation are comparable to that determined by the experiments. The isotherm models are shown in 
Figure 5.15, Figure 5.16, Figure 5.17, and Figure 5.18 and the modeling results are listed in Table 5.7, Table 5.8, Table 5.9 and Table 5.10.

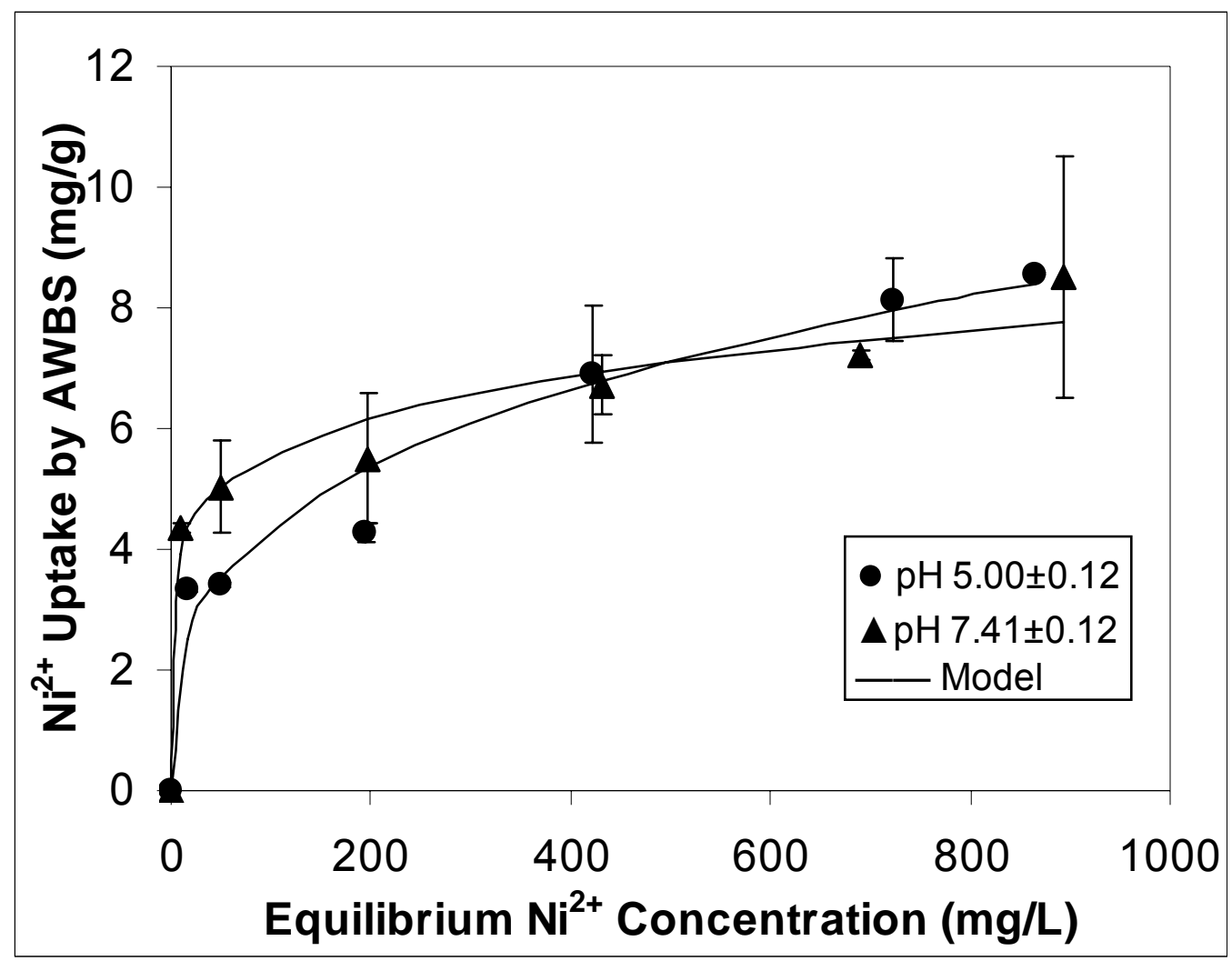

Figure 5.15: Simulation Results Using the Freundlich Equation (room temperature)

Table 5.7: Simulation Results Using the Freundlich Equation (room temperature)

\begin{tabular}{ccccc}
\hline $\mathbf{p H}$ & $\mathbf{k}(\mathbf{m g} / \mathbf{g})$ & $\mathbf{n}$ & $\mathbf{r}^{2}$ & $\begin{array}{c}\text { Relative } \\
\text { Error (\%) }\end{array}$ \\
\hline $5.00 \pm 0.12$ & $1.060 \pm 0.291$ & $0.306 \pm 0.044$ & 0.9668 & 8.5 \\
$7.41 \pm 0.12$ & $2.772 \pm 0.423$ & $0.152 \pm 0.026$ & 0.9715 & 5.4 \\
\hline
\end{tabular}




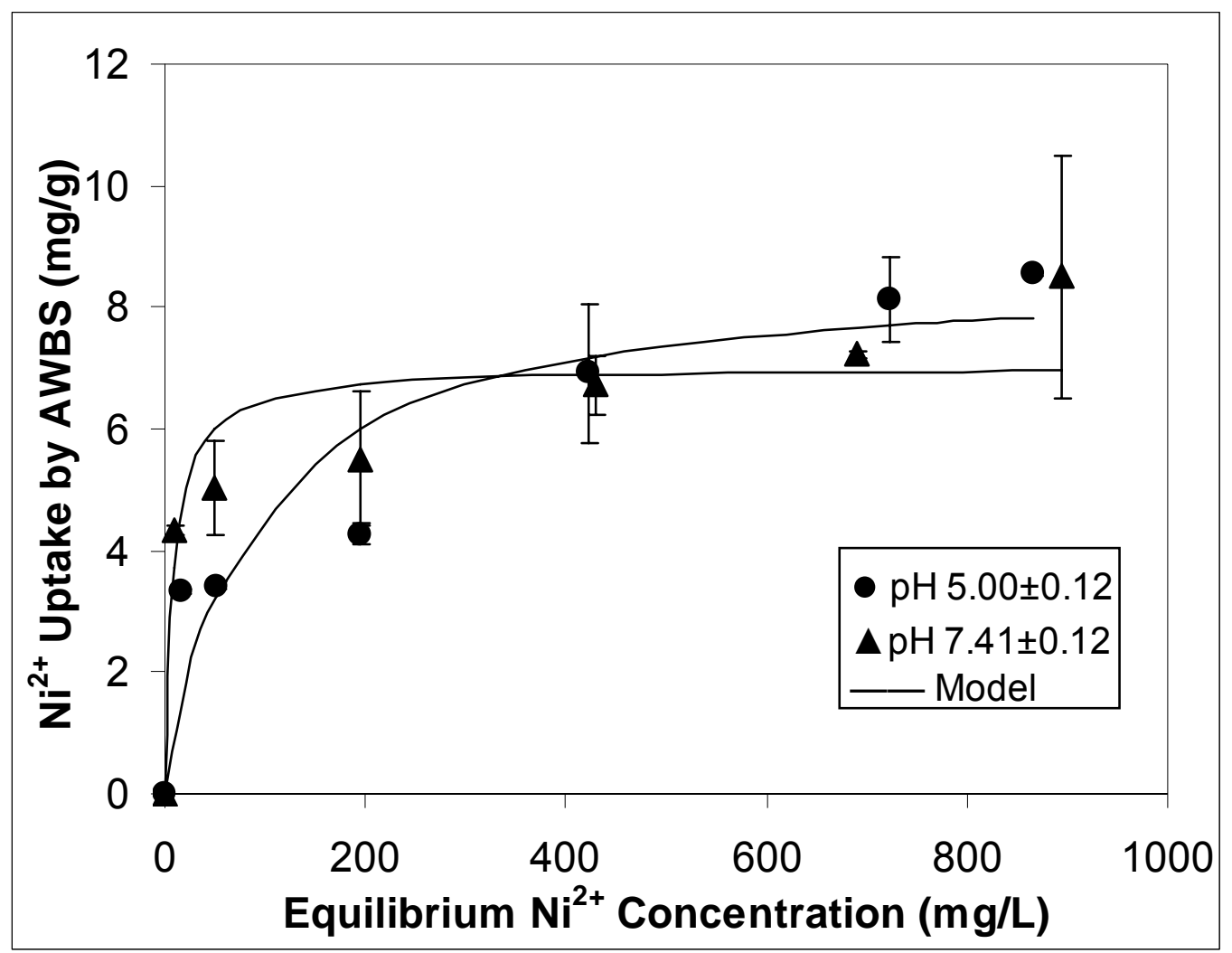

Figure 5.16: Simulation Results Using the Langmuir Equation (room temperature)

Table 5.8: Simulation Results Using the Langmuir Equation (room temperature)

\begin{tabular}{ccccc}
\hline $\mathbf{p H}$ & $\mathbf{a}$ & $\mathbf{b}$ & $\mathbf{r}^{2}$ & $\begin{array}{c}\text { Relative } \\
\text { Error (\%) }\end{array}$ \\
\hline $5.00 \pm 0.12$ & $5.771 \pm 1.328$ & $(-) 8189936.6162 \pm 1.4894 \mathrm{E}+014 *$ & 0.5013 & 17.2 \\
$7.41 \pm 0.12$ & $6.222 \pm 0.723$ & $(-) 1270799.0161 \pm 4.5109 \mathrm{E}+012 *$ & 0.7354 & 11.5 \\
\hline
\end{tabular}

* Negative values are unrealistic, indicating poor fitting of the Langmuir model 


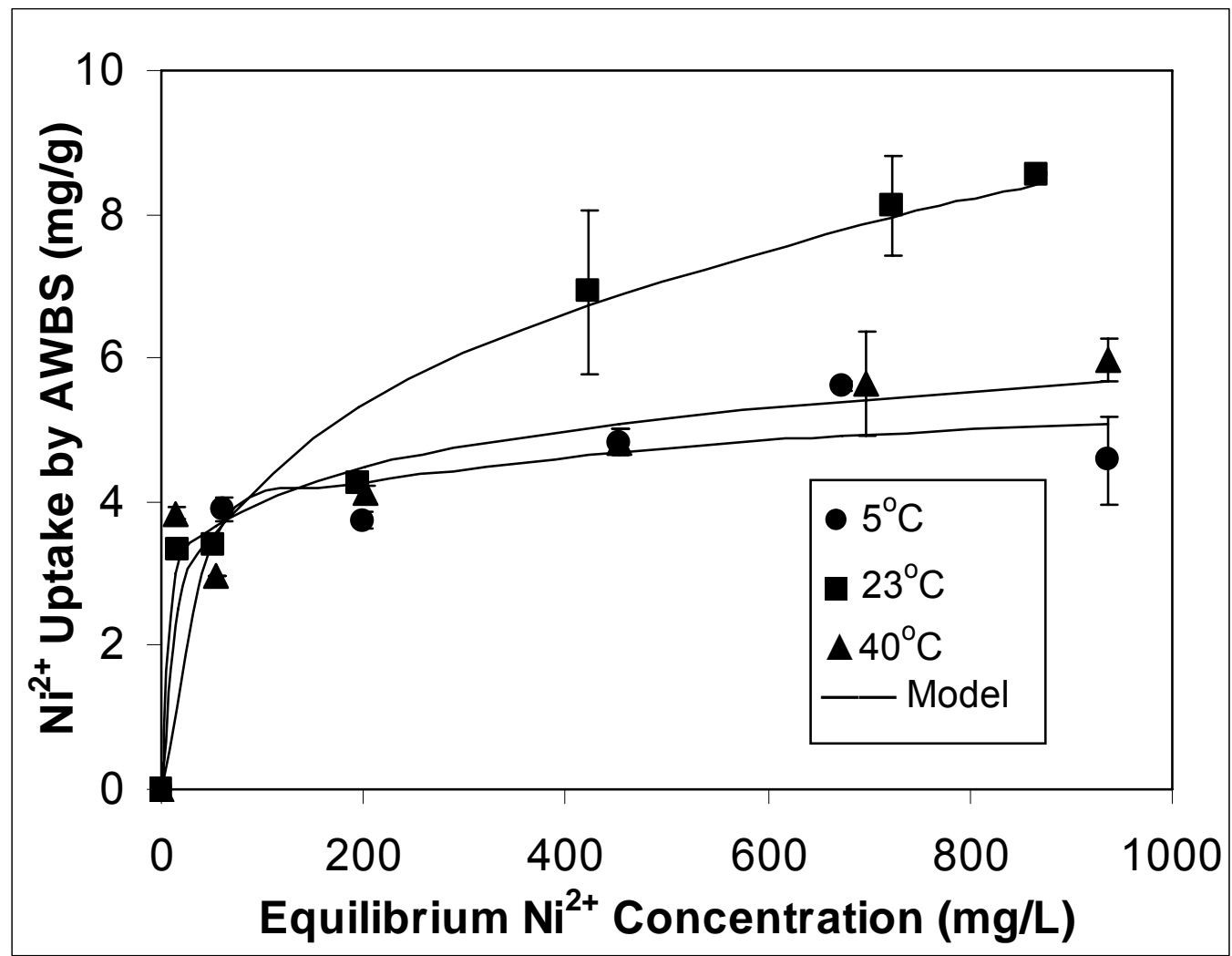

Figure 5.17: Simulation Results Using the Freundlich Equation (pH 5.0 \pm 0.1 )

Table 5.9: Simulation Results Using the Freundlich Equation (pH 5.0 \pm 0.1 )

\begin{tabular}{ccccc}
\hline Temp. & $\mathbf{k}(\mathbf{m g} / \mathbf{g})$ & $\mathbf{n}$ & $\mathbf{r}^{2}$ & $\begin{array}{c}\text { Relative } \\
\text { Error (\%) }\end{array}$ \\
\hline $5 \pm 1^{\circ} \mathrm{C}$ & $2.312 \pm 0.799$ & $0.115 \pm 0.057$ & 0.9439 & 7.5 \\
$23 \pm 1^{\circ} \mathrm{C}$ & $1.059 \pm 0.291$ & $0.306 \pm 0.044$ & 0.9668 & 8.5 \\
$40 \pm 1^{\circ} \mathrm{C}$ & $1.988 \pm 0.472$ & $0.153 \pm 0.040$ & 0.9377 & 9.7 \\
\hline
\end{tabular}




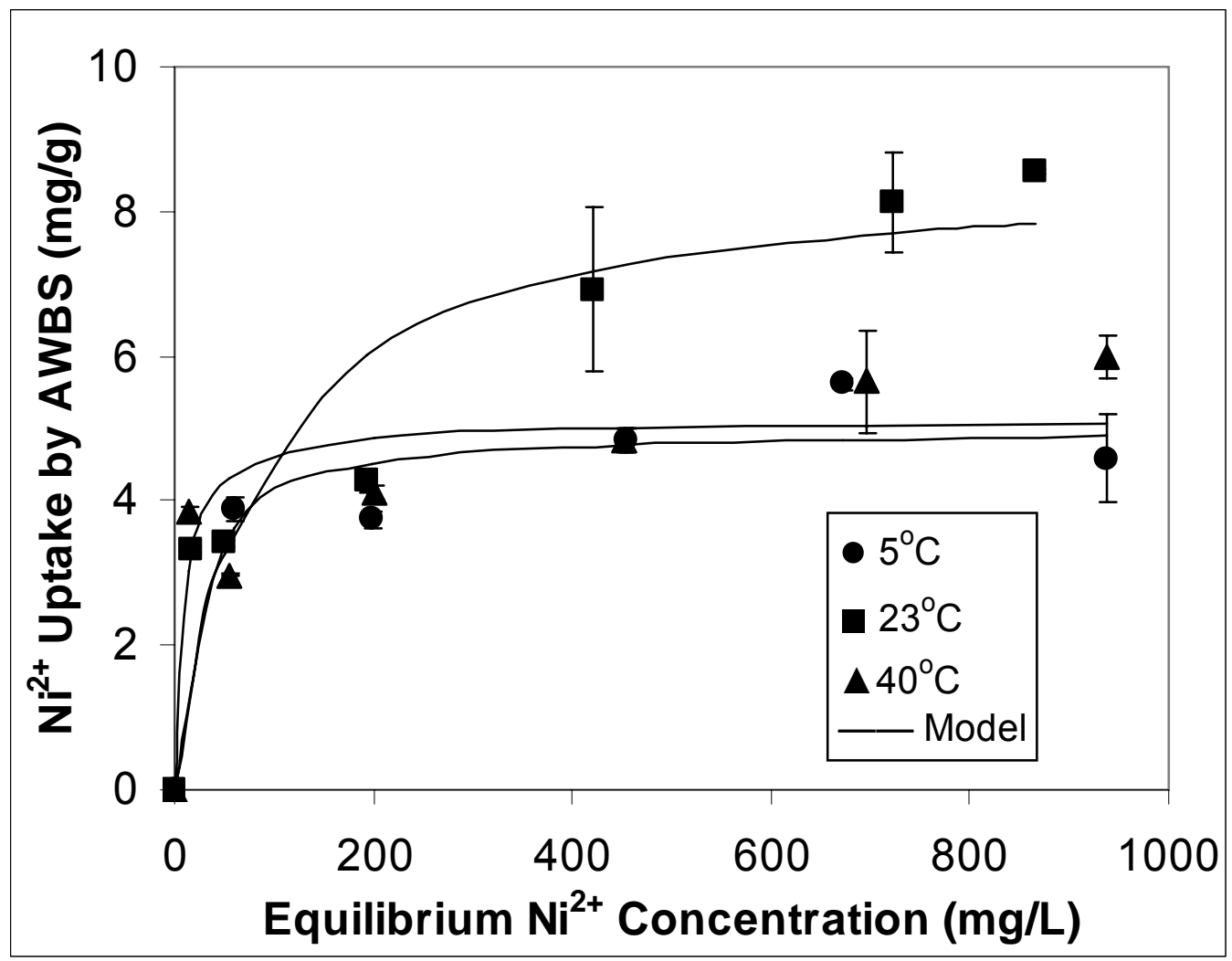

Figure 5.18: Simulation Results Using the Langmuir Equation ( $\mathrm{pH} 5.0 \pm 0.1$ )

Table 5.10: Simulation Results Using the Langmuir Equation ( $\mathrm{pH} 5.0 \pm 0.1$ )

\begin{tabular}{ccccc}
\hline Temp. & a & b & $\mathbf{r}^{2}$ & $\begin{array}{c}\text { Relative } \\
\text { Error (\%) }\end{array}$ \\
\hline $5 \pm 1^{\circ} \mathrm{C}$ & $4.530 \pm 0.411$ & $(-) 381889.4850 \pm 1.8648 \mathrm{E}+012^{*}$ & 0.8812 & 8.1 \\
$23 \pm 1^{\circ} \mathrm{C}$ & $5.771 \pm 1.327$ & $(-) 8189936.6162 \pm 1.4894 \mathrm{E}+014^{*}$ & 0.5013 & 17.2 \\
$40 \pm 1^{\circ} \mathrm{C}$ & $4.563 \pm 0.601$ & $(-) 756052.9498 \pm 2.4087 \mathrm{E}+012^{*}$ & 0.7333 & 16.2 \\
\hline
\end{tabular}

* Negative values are unrealistic, exhibiting poor fitting of the Langmuir model 


\subsection{Desorption of Nickel Adsorbed on AWBS}

Desorption experiments were conducted by using dilute hydrochloric acid solution at $\mathrm{pH} 2.0 \pm 0.1$. A known quantity ( $0.25 \mathrm{~g})$ of nickel loaded AWBS was eluted by $10 \mathrm{ml}$ acid solution at the above mentioned $\mathrm{pH}$; the volume of the solution was selected based on the minimum quantity of liquid required to immerse and well mix the biomass. Desorption efficiency was found to be $86 \%$ (The ratio of eluted nickel from the nickel-loaded biosorbent to that loaded nickel is called as elution or desorption efficiency). Niu (2002) achieved $100 \%$ elution with the crab shells and proved physical adsorption mechanism. In the case of AWBS, there were no strong evidences to confirm whether nickel ion adsorption is chemisorption or physical adsorption. This has to be further investigated.

\subsection{Fourier Transform Infra Red Spectroscopy Analysis (FT-IR)}

The FT-IR spectra of barley straw control and $\mathrm{Ni}^{2+}$-loaded barley straw are offset arbitrarily in order to identify changes of the spectra in Figure 5.19. It shows the most prominent peaks in the region $1742-1620 \mathrm{~cm}^{-1}$, originating from the stretching mode of carbonyls, mainly ketones, expected from carboxyl and amide groups of protein (Stuart 2004; Himmelsbach 2002). The change in magnitude of these vibration bands in the FT-IR spectrum of nickel loaded barley straw indicate the participation of carboxyl and amide groups of cellulose, hemi-cellulose and protein in the nickel biosorption mechanism by barley straw. 


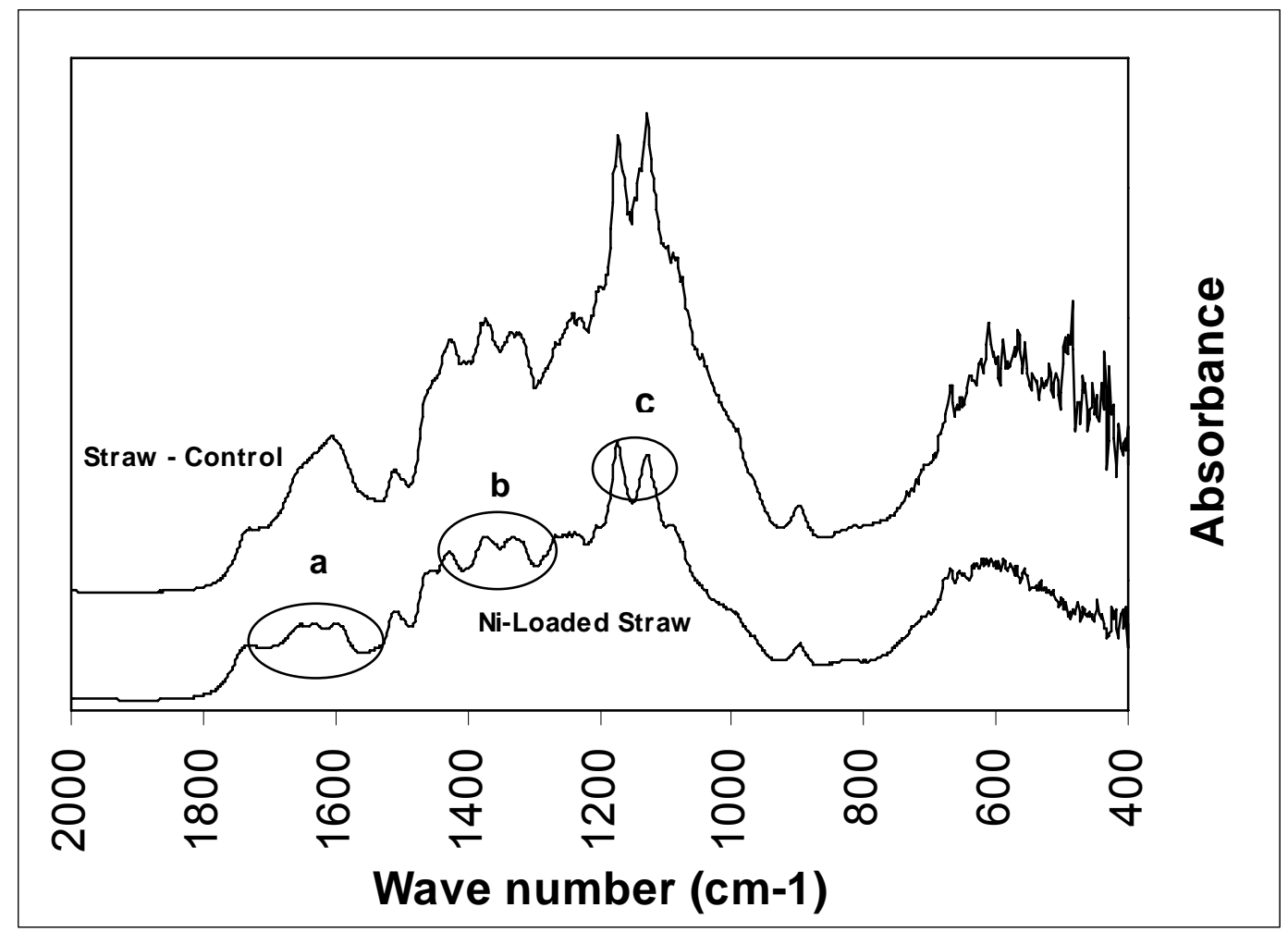

Figure 5.19: FT-IR Spectra of Barley Straw Control and $\mathrm{Ni}^{2+}$-Loaded Barley Straw (8.45 mg $\mathrm{Ni}^{2+} / g$ dry straw.). (a), (b), and (c): change in absorbance of Vibrational bands.

The FT-IR study also demonstrates that the peaks in $1680-1600 \mathrm{~cm}^{-1}$ representing $\mathrm{C}=\mathrm{C}, \mathrm{C}-\mathrm{H}$ or $\mathrm{O}-\mathrm{H}$ bending frequencies which are indicators of lignin (Stuart 2004; Himmelsbach 2002; Moore 2002; Xiao 2001). Change in absorbance in this region indicates the role of lignin in nickel binding by barley straw. The results indicate that hydroxyl (-OH), carboxyl (-COOH) or amide group may play a role in nickel adsorption. In addition, the stretching at $1360-1300 \mathrm{~cm}^{-1}$ indicates C-N stretching bands of aromatic amines and the stretching at $1170-1120 \mathrm{~cm}^{-1}$ indicates aliphatic amines (Stuart 2004). The characteristic peak in the region $1430 \mathrm{~cm}^{-1}$ indicates $\mathrm{C}-\mathrm{O}-\mathrm{H}$ in plane bending of carboxylic 
acids of cellulose and hemi-cellulose. The stretching in $1300 \mathrm{~cm}^{-1}$ and $1170 \mathrm{~cm}^{-1}$ also indicates alcohols and phenols of lignin. The change in absorbance of these peaks indicates that cellulose, hemi-cellulose, protein and lignin might involve in nickel ions binding by barley straw. 


\section{CONCLUSIONS AND RECOMMANDATIONS}

\subsection{Conclusions}

Barley straw is capable of adsorbing and removing nickel from the simulated nickel plating wastewater. The point of zero net charge of AWBS was found to be around pH 4.4. Kinetic studies revealed that the adsorption process was rapid and the system reached equilibrium in about an hour. The adsorption rate was faster when the barley straw particles are smaller in size. Although an increase in pH from 5 to 7 did not show any significant change in the rate of adsorption, it resulted in higher equilibrium nickel uptake. For the first time, it was demonstrated that the external mass transfer model was able to fit the initial data points of nickel adsorption and provide acceptable volumetric mass transfer coefficient values.

The equilibrium uptake was significantly affected with an increase in ionic strength from less than $0.02 \mathrm{M}$ to $0.2 \mathrm{M}$. Decrease in biosorbent particle size from 1.18-3.35 mm to less than $0.425 \mathrm{~mm}$ increased equilibrium nickel uptake. Control experiments revealed that no nickel ions precipitated at $\mathrm{pH}$ values lower than 8. An increase in temperature from $23^{\circ} \mathrm{C}$ to $40^{\circ} \mathrm{C}$ significantly affected the equilibrium nickel uptake, and indicates that nickel adsorption is exothermic. The Freundlich isotherm model exhibited a better fit than the Langmuir model with an average relative error of less than $10 \%$.

The FT-IR studies indicated the participation of cellulose, hemi-cellulose, protein and lignin in nickel biosorption by barley straw. The nickel ion uptake of $8.45 \mathrm{mg} / \mathrm{g}$ from 
this work is slightly higher than that of rice husk $(5.5 \mathrm{mg} / \mathrm{g})$ and Brazil nut shells (7.9mg/g); however, it is lower than orange peel $(75.2 \mathrm{mg} / \mathrm{g})$ and rice bran $(44.8 \mathrm{mg} / \mathrm{g})$. Barley straw possesses the advantage of inhibiting the growth of algae; hence it has the potential for treating wastewater streams. 


\subsection{Recommendations for Future Work}

The present work reports single (nickel) metal biosorption by barley straw only. However, the actual plating wastewater contains many other heavy metal ions such as chromium $(\mathrm{Cr})$, copper $(\mathrm{Cu})$, Zinc $(\mathrm{Zn})$, iron $(\mathrm{Fe})$ and lead $(\mathrm{Pb})$; in order to implement barley straw biosorption process, the multi-metal adsorption by the straw needs to be studied; this study may also give information about the metal of preference by barley straw. Although barley straw and the compounds released by the straw are non toxic to the environment, the actual compounds released by the straw has to be thoroughly studied, this may give some information about how the straw restricts the growth of algae. Nickel uptake by barley straw is not high enough to use the straw as a sole adsorbent. Further studies may be carried out to use a combination of biosorbents to effectively remove metals from the effluents. Barley straw may remove entire nickel ions completely, when the initial concentration was $25 \mathrm{mg} / \mathrm{L}$. Hence, it is important to carry out an adsorption study on the partially treated effluents which contain trace quantities (around $25 \mathrm{mg} / \mathrm{L}$ ) of heavy metals using the straw. As barley straw is considered safe for the environment and aquatic life, apart from metal sequestration, research may be carried out to use barley straw as an adsorbent to treat the emerging pollutants of severely contaminated water bodies. For example naphthenic acids; enormous volumes of naphthenic acids containing wastewater have been generated during the production of petroleum from oil sands. Numerous ponds contain this kind of contaminated water in Alberta, which is a great environmental threat. It is imperative to study barley straw biosorption on these wastewaters. 


\section{REFERENCES}

Ahalya, N., Kanamadi, R.D., and Ramachandra, T.V. (2005). "Biosorption of chromium (VI) from aqueous solutions by the husk of Bengal gram (Cicer arientinum)." Electron. J. Biotechn. 8: 258-264.

Akhtar, N., Iqbal,J., and Iqbal, M. (2004). "Removal and recovery of nickel(II) from aqueous solution by loofa sponge-immobilized biomass of Chlorella sorokiniana: characterization studies." J. Hazard. Mater. B(108): 85-94.

Al-Asheh, S. and Z. Duvnjak (1999). "Sorption of heavy metals by canola meal." Water. Air. Soil. Poll. 114: 251-276.

Antunes, W. M., Luna, A.S., Henriques, C.A. and A. C. A. Costa (2003). "An evaluation of copper biosorption by a brown seaweed under optimized conditions." Electron. J. of Biotechn.. 6(3).

ASTM (2004). "Standard method for ash in the analysis sample of coal and coke." Am. Soc.Test.Mater., International, Philadelphia, PA D: 3174-04.

Basso, M. C., Cerrella, E.G., and Cukierman, A.L. (2002). "Lignocellulosic Materials as Potential Biosorbents of Trace Toxic Metals from Wastewater." Ind. Eng. Chem. Res. 41: 3580-3585.

Bolger, P. T., and Szlag, D. C. (2002). "Electrochemical treatment and reuse of nickel plating rinse waters." Environ. Progr. 21( 3): 203 - 208. 
Brownlee, E. F., Sellner, S.G., and Sellner, K.G. (2003). "Effects of barley straw (Hordeum vulgare) on freshwater and brackish phytoplankton and cyanobacteria." J. Appl. Phycol. 15: 525-531.

Buffle, J. (1988). Complexation reactions in aquatic systems: An analytical approach, . Chichester, U.K, Ellis Horwood Ltd.

Cgiar. (2005). "Areas of research - Fact sheets, http://www.cgiar.org/impact/research/." Consultative Group on International Agricultural Research (CGIAR) Retrieved 2007, February 26.

Chojnacka, K. (2006). "Biosorption of Cr (III) Ions by wheat straw and grass: a systematic characterization of new biosorbents." Pol. J. of Environ. Stud. 15(6): 845-852.

Cossich, E. S., Tavares, C.R.G., and Ravagnani, T.M.K. (2002). "Biosorption of chromium(III) by Sargassum sp. biomass." Electron. J. Biotechn.. 5(2).

Daifullah, A. A. M., B. S. Girgis and H. M. H. Gad (2004). "A study of the factors affecting the removal of humic acid by activated carbon prepared from biomass material." Coll. Surf..A. 235(1-3): 1-10.

Davis, J. A., and Leckie, J.O. (1978). "Surface ionization and complexation at the oxidewater interface: 2. Surface properties of amorphous iron oxyhydroxide and adsorption of metal ions." J. Coll. Inter. Sci. 67: 90-107.

Davis, T. A., Volesky, B., and Mucci, A. (2003). "A review of the biochemistry of heavy metal biosorption by brown algae." Water. Res. 37(18): 4311-4330.

Dean, J. A. (1999). Lange's Handbook of Chemistry (15th Edition), McGraw-Hill.

Doniec, A. (2008). "A cellular concrete material used for thorough cleaning of wastewater generated in electroplating process." Clean. Techn. Environ. Policy. 10: 263-268. 
El Hajjami, A., M. P. Gigandet, M. De Petris-Wery, J. C. Catonne, J. J. Duprat, L. Thiery, F. Raulin, B. Starck and P. Remy (2008). "Hydrogen permeation inhibition by zincnickel alloy plating on steel XC68." Appl. Surf. Sci. 255(5): 1654-1660.

Fiol, N., Villaescusa, I., Martinez, M., Miralles, N., Poch, J., and Serarols, J. (2006). "Sorption of $\mathrm{Pb}(\mathrm{II}), \mathrm{Ni}(\mathrm{II}), \mathrm{Cu}(\mathrm{II})$ and $\mathrm{Cd}(\mathrm{II})$ from aqueous solution by olive stone waste." Separ. Purif. Tech. 50(1): 132-140.

Fogler, H. S. (1999). Elements of chemical reaction engineering New Jersey, Prentice-Hall, Inc.

Force, T. M. F. P. P. T. (2001). "The metal finishing industry pollution prevention project 2001." http://www.c2p2online.com/documents/Finishing8thProgressReport.doc.

Freundlich, H. (1907). "Ueber die Adsorption in Loesungen." Z. Phys. Chem. 57: 385-470.

Gardea-Torresdey, J. L., Tiemann, K.J., Armendariz, V., Oberto, L.B., Chianelli, R.R., Rios, J., Parsons, J.G., and Gamez, G. (2000). "Characterization of Cr(VI) binding and reduction to $\mathrm{Cr}$ (III) by the agricultural byproducts of Avena mondia (Oat) biomass " J. Hazard. Mater. B80: 175-188.

Hanif, M. A., Nadeem, R., Bhatti, H. N., Ahmad, N. R., and Ansari, T. M. (2007). "Ni(II) biosorption by Cassia fistula (Golden Shower) biomass." J. Hazard. Mater. 139(2): 345-355.

Himmelsbach, D. S., Khalili, S., Akin, D.E. (2002). "The use of FT-IR microspectroscopic mapping to study the effects of enzymatic retting of flax (Linum usitatissium L.) stems." J. Sci. Food Agric. 82: 685-696.

Ho, Y. (2006). "Review of second-order models for adsorption systems." J. Hazard. Mater. B136: 681-689. 
Holan, Z. R., and Volesky, B. (1994). "Biosorption of Lead and Nickel by Biomass of Marine-Algae." Biotechnol. Bioeng. 43(11): 1001-1009.

Holan, Z. R., Volesky, B., and Prasetyo, I. (1993). "Biosorption of Cadmium by Biomass of Marine-Algae." Biotechnol. Bioeng. 41(8): 819-825.

Karppinen, T. H., and Yli-Pentti, A. (2000). "Evaluation of selective ion exchange for nickel and cadmium uptake from the rinsewaters of a plating shop." Sep. Sci. Tech. 35: $1619-1633$.

Kim, J. H. and I. S. Hwang (2008). "Electroless nickel-plating for the PWSCC mitigation of nickel-base alloys in nuclear power plants." Nucl. Eng. Des. 238(10): 2529-2535.

Koumanova, B., P. Peeva, S. J. Allen, K. A. Gallagher and M. G. Healy (2002). "Biosorption from aqueous solutions by eggshell membranes and Rhizopus oryzae: equilibrium and kinetic studies." J. Chem. Technol. Biot. 77(5): 539-545.

Krishnani, K. K., Meng, X., Christodoulatos,C., and Boddu,V.M. (2008). "Biosorption mechanism of nine different heavy metals onto biomatrix from rice husk." $\underline{J}$. Hazard. Mater. 153: 1222-1234.

Kulp, K., and Ponte, J.G.J. (2000). Handbook of cereal science and technology. New York, Marcel Dekker Inc.

Langmuir, I. (1918). "The adsorption of gases on plane surfaces of glass, mica and platinum." J. Am. Chem. Soc. 40: 1361-1403.

Larsen, V. J., and Schierup, H.H. (1981). "The use of straw for removal of heavy metals from waste water." J. Environ. Qual. 10(2): 188-193.

Lee, B. G., and Rowell,R.M. (2004). "Removal of heavy metal ions from aqueous solutions using lignocellulosic fibers." J. Nat. Fibers 1: 97-108. 
Leusch, A., Z. R. Holan and B. Volesky (1995). "Biosorption of Heavy-Metals (Cd, Cu, $\mathrm{Ni}, \mathrm{Pb}, \mathrm{Zn}$ ) by Chemically-Reinforce Biomass of Marine-Algae." $\underline{\text { J. Chem. }}$ Technol. Biot. 62(3): 279-288.

Li, X., Tang, Y., Cao, X., Lu, D., Luo, F., and Shao, W. (2008). "Preparation and evaluation of orange peel cellulose adsorbents for effective removal of cadmium, zinc, cobalt and nickel." Coll. Surf. A.. 317(1-3): 512-521.

Lindsey, T. C., and Randall, P.M. (1993). "Recycling nickel electroplating rinse waters by low temperature evaporation and reverse osmosis." $\underline{\text { U. S. EPA Technical Report }}$ EPA/600/R-693/160.

Lo’́pez, S., Davies, D.R., Gira’́ ldez, F.J., Dhanoa, M.S., Dijkstra, J., and France, J. (2005). "Assessment of nutritive value of cereal and legume straws based on chemical composition and in vitro digestibility." J. Sci. Food. Agric.. 85: 1550-1557.

Loukidou, M. X., T. D. Karapantsios, A. I. Zouboulis and K. A. Matis (2004). "Diffusion kinetic study of cadmiurn(II) biosorption by Aeromonas caviae." J. Chem. Technol. Biot. 79(7): 711-719.

Mani, S., Tabil, L.G., and Sokhansanj, S. (2002). "Compaction behavior of some biomass grinds." AIC 2002 Meeting, CSAE/SCGR Paper No. 02-305.

Maurya, N. S., and Mittal, A.K. (2006). "Applicability of equilibrium isotherm models for the biosorptive uptakes in comparison to activated carbon-base adsorption." $\underline{\mathrm{J}}$. Environ. Eng. 132(12): 1589-1599.

Miralles, N., Martinez, M., Florido, A., Casas, I., Fiol, N., and Villaescusa, I. (2008). "Grape stalks waste as low cost biosorbents: An alternative for metal removal from aqueous solutions." Solvent Extr.Ion Exc. 26(3): 261-270. 
Moore, A. K., Owen, N.L. (2002). "Infrared spectroscopic studies of solid wood." Appl. Spectrosc. Rev. 36: 65-86.

Naik, S., V. V. Goud, P. K. Rout and A. K. Dalai (2009). "Characterization of Canadian Biomass for Alternative Renewable Biofuel." Renew. Energ: Submitted.

Niu, H. (2002). Biosorption of Anionic Metal Species, PhD Thesis. Chemical Engineering. Montreal, Canada, McGill University.

Niu, H., and Volesky, B. (2001). "Gold adsorption from cyanide solution by chitinous material." J. Chem. Technol. Biotechnol. 76(3): 291-297.

Niu, H., and Volesky, B. (2003). "Biosorption mechanism of anionic metal species with waste crab shells." Eur. J. Mineral Proc. \& Envir. Protect. 3(1): 75-87.

Niu, H., and Volesky, B. (2003). "Characteristics of anionic metal species biosorption with waste crab shells." Hydrometallurgy 71(1-2): 209-215.

Niu, H., Xu, X.S., Wang, J.H., and Volesky, B. (1993). "Removal of lead from aqueous solutions by Penicillium biomass." Biotechnol. Bioeng. 42(6): 785-787.

Ofomaja, A. E. and Y. S. Ho (2008). "Effect of temperatures and $\mathrm{pH}$ on methyl violet biosorption by Mansonia wood sawdust." Biores. Tech. 99(13): 5411-5417.

Oraedu, C. and C. H. Niu (2008). Characterization of Biosorbents. 58th Canadian Chemical Engineering Conference, Ottawa, Ontario, Canada.

Ozer, A., and Ozer, D. (2003). "Comparative study of the biosorption of $\mathrm{Pb}(\mathrm{II}), \mathrm{Ni}(\mathrm{II})$ and $\mathrm{Cr}(\mathrm{VI})$ ions onto S-cerevisiae: determination of biosorption heats." ․ Hazard. Mater. 100(1-3): 219-229. 
Pamukoglu, M. Y. and F. Kargi (2007). "Cu(II) ion recovery by biosorption onto powdered waste sludge (PWS) in a fed-batch reactor: Particle size effects." Separ. Sci. Tech. 42(2): 285-298.

Pehlivan, E., T. Altun and S. Parlayici (2009). "Utilization of barley straws as biosorbents for $\mathrm{Cu}^{2+}$ and $\mathrm{Pb}^{2+}$ ions." J. Hazard. Mater. 164(2-3): 982-986.

Puranik, P. R., J. M. Modak and K. M. Paknikar (1999). "A comparative study of the mass transfer kinetics of metal biosorption by microbial biomass." Hydrometallurgy 52(2): 189-197.

Qi, B. C., and Aldrich, C. (2008). "Biosorption of heavy metals from aqueous solutions with tobacco dust." Biores. Tech. 99: 5595-5601.

Rahman, M. S. and M. R. Islam (2009). "Effects of pH on isotherms modeling for $\mathrm{Cu}(\mathrm{II})$ ions adsorption using maple wood sawdust." Chem. Eng. J. 149(1-3): 273-280.

Richardson-Boedler., C. (2007). "Metal passivity as mechanism of metal carcinogenesis: Chromium, nickel, iron, copper,cobalt, platinum, molybdenum." Toxicol. Environ. Chem. 89(1): 15-70.

Roberts, G. A. F. (1992). Chitin Chemistry. London, UK, Macmillan,.

Robinson, T., Chandran, B., and Nigam, P. (2002). "Removal of dyes from a synthetic textile dye effluent by biosorption on apple pomace and wheat straw." Water. Res. 36: $2824-2830$.

Schiewer, S. (1996). "Multi-metal ion exchange in biosorption." Chemical Engineering, McGill University, Montreal, Canada.

Shuler, M. L. and F. Kargi (2006). Bioprocess Engineering. London, Pearson Prentice Hall. 
Stuart, B. (2004). Infrared spectroscopy: fundamentals and applications. Sydney, Australia, John Wiley \& Sons, Ltd.

Tobin, J. M., Cooper, D. G., and Neufeld, R. J. (1984). "Uptake of Metal-Ions by Rhizopus-Arrhizus Biomass." Appl. Environ. Microbiol. 47(4): 821-824.

Tracey, V. A. (1988). "The More Exotic Uses of Nickel Powders." Powder. Metall. 31(4): 253-255.

University of Saskatchewan (2002). "Cereal crops." University of Saskatchewan, http://interactive.usask.ca/Ski/agriculture/crops/cereals/ Retrieved 2007, February 26.

Uslu, G., and Tanyol, M. (2006). "Equilibrium and thermodynamic parameters of single and binary mixture biosorption of lead(II) and copper(II) ions onto Pseudomonas putida: Effect of temperature." J. Hazard. Mater. B(135): 87-93.

Vega, F. A., E. F. Covelo and M. L. Andrade (2009). "Effects of sewage sludge and barley straw treatment on the sorption and retention of $\mathrm{Cu}$, $\mathrm{Cd}$ and $\mathrm{Pb}$ by coppermine Anthropic Regosols." J.Hazard. Mater 169(1-3): 36-45.

Vijayaraghavan, K., Palanivelu, K., and Velan, K. M. (2005). "Crab shell-based biosorption technology for the treatment of nickel-bearing electroplating industrial effluents." J. Hazard. Mat. 119: 251-254.

Viraraghavan, T., and Dronamraju, M.M. (1993). "Removal of copper, nickel and zinc from wastewater by adsorption using peat moss." J. Environ. Sci. Health A28(6): 1261-1276.

Volesky, B. (1990). "Biosorption by fungal biomass. in B. Volesky ed. Biosorption of Heavy Metals." CRC Press, Boca Raton, FL: 139-172. 
Volesky, B. (1990). "Biosorption of Heavy Metals." CRC Press, Boca Raton, FL.

Volesky, B. (2003). Sorption and Biosorption. Montreal, Canada, BV Sorbex.

Wisniewska, S. K., J. Nalaskowski, E. Witka-Jezewska, J. Hupka and J. D. Miller (2003). "Surface properties of barley straw." Coll. and Surf. B-Biointerf. 29(2-3): 131-142.

Xiao, B., Sun, X.F., Sun, R.C. (2001). "Chemical, structural and thermal characterization of alkali soluble lignins, hemicelluloses and cellulose from maize stems, rye straw and rice straw." Polym Degrad. Stab. 74: 307-319.

Zafar, M. N., Nadeemb, R., and Hanif, M.A (2007). "Biosorption of nickel from protonated rice bran." J. Hazard. Mater. 143: 478-485.

Zhou, M., Liu, Y., Zeng, G., Li, X., Xu, W. and T. Fan (2007). "Kinetic and equilibrium studies of $\mathrm{Cr}(\mathrm{VI})$ biosorption by dead Bacillus licheniformis biomass " World J. Microbiol Biotechnol(23): 43-48. 